\title{
1 A Climatology of Tropospheric Humidity Inversions 2 in Five Reanalyses
}

3 Michael A. Brunke ${ }^{\mathrm{a}, *}$, Steve T. Stegall ${ }^{\mathrm{b}}$, Xubin Zeng ${ }^{\mathrm{a}}$

$4{ }^{a}$ Department of Atmospheric Sciences, The University of Arizona, Tucson, Arizona, USA

5 b Department of Energy and Environmental Systems, North Carolina A\&T State University, 6 Greensboro, North Carolina, USA

* Corresponding author at: Department of Atmospheric Sciences, The University of Arizona,

9 P.O. Box 210081, Tucson, AZ 85721-0081 USA. Tel.: +520 626-7349 (office); fax: +520 621-

10 6833. E-mail address: brunke@atmo.arizona.edu (M. A. Brunke). 


\section{Abstract}

Specific humidity is generally thought to decrease with height in the

47 troposphere. However, here we document the existence of specific humidity inversions in five

48 reanalyses: the National Centers for Environmental Prediction (NCEP) second reanalysis

49 (NCEP-2), the European Centre for Medium-Range Forecasts (ECMWF) 40-year reanalysis

50 (ERA-40), the Modern Era Retrospective Analysis for Research Applications (MERRA),

51 NCEP’s Climate Forecast System Reanalysis (CFSR), and the ECMWF interim reanalysis

52 (ERA-Interim). These inversions are most frequent in the polar regions. Inversions do occur

53 elsewhere, most notably over the subtropical stratus regions, but are less frequent and likely

54 overproduced depending on the location. Polar inversions are the most persistent in winter and

55 the strongest (as defined by the humidity difference divided by the pressure difference across the

56 inversion) in summer or autumn with low bases (at pressures $>900 \mathrm{hPa}$ ). Winter humidity

57 inversions are lower, being near-surface, due to the persistence of low-level temperature

58 inversions associated with these humidity inversions, while summer humidity inversions tend to

59 be located near cloud top providing moisture to prevent the melt season stratus from

60 evaporating. The most important contributions to affect humidity inversions in MERRA are

61 dynamics, turbulence, and moist physics. However, local advection may not play as much of a

62 role as regional humidity convergence. The subtropical stratus inversions are as thick as polar

63 humidity inversions but with higher bases generally at pressures $<900 \mathrm{hPa}$. These inversions are

64 confirmed by rawinsonde data, but there are discrepancies between the observed annual and

65 diurnal cycle in inversion frequency and those portrayed in the reanalyses.

66 Keywords: specific humidity inversions; climatology; reanalyses; polar regions; subtropical

67 stratus

68 


\section{Introduction}

The vertical distribution of water vapor strongly affects radiative transfer as well as cloud

71 and precipitation formation and hence plays a fundamental role in weather forecasting and

72 climate studies. It is generally thought that specific humidity decreases with increasing height in

73 the troposphere (e.g., Fig. 12.4 in Peixoto and Oort, 1992; Wagner et al., 1990; Johnsen and

74 Rockel, 2001). On average, this is indeed the case as can be seen in the profile of the zonal mean

75 of specific humidity from the National Aeronautics and Space Administration (NASA) Goddard

76 Modeling and Assimilation Office (GMAO) Modern Era Retrospective Analysis for Research

77 and Applications (MERRA) in Fig. 1.

78 However, in certain circumstances there can be specific humidity inversions, or layers in

79 which specific humidity increases with height, in the troposphere. Fig. 2 presents the zonal mean

80 of the vertical profiles of the difference in specific humidity $\Delta q$ with height in MERRA for each

81 season: (a) December-February or DJF, (b) March-May or MAM, (c) June-August or JJA, and

82 (d) September-November or SON. This $\Delta q$ is calculated at halfway between each pressure level

83 in MERRA as the simple difference in specific humidity between pressure levels. Now, one can

84 clearly see the areas of positive $\Delta q$, i.e. increasing humidity with height, as the blue shading in

85 the polar regions. Over the Antarctic, positive $\Delta q$ is only over the South Pole from austral

86 autumn (MAM) to spring (SON). Over the Arctic, the largest area of positive $\Delta q$ occurs in

87 boreal winter (DJF). In boreal spring (MAM) and summer (JJA), there is no mean positive $\Delta q$,

88 and the area of mean positive $\Delta q$ redevelops in boreal autumn (SON). This seems to indicate

89 that humidity inversions would be more numerous in the polar regions during the autumn and

90 winter seasons but does not preclude the existence of humidity inversions in those regions in any 
91 other season. Humidity inversions may be less numerous or not strong enough to withstand the 92 averaging.

93 Previously, specific humidity inversions were observed periodically during the Arctic

94 Ocean Experiment 2001 (Tjernström et al., 2004; Tjernström, 2005; Sedlar and Tjernström, 95 2009), and Gerding et al. (2004) documented the case of a moister layer above a near-surface dry 96 layer observed by lidar on 28 February 2002 on the island of Spitsbergen in the Arctic. More 97 recently, Vihma et al. (2011) investigated humidity inversions over two Svalbard fjords finding 98 that they were connected to temperature inversions occurring simultaneously which was also 99 found by Sedlar et al. (2011) from observations made during two field experiments over the 100 Arctic Ocean. Arctic humidity inversions were also previously documented by Serreze et al. 101 (1995) and modeled by Curry (1983).

102 These inversions are not limited to the Arctic. Near-surface humidity inversions can be 103 seen from three years of summer and autumn radiosonde profiles over Dome C (Tomasi et al., 104 2006) and in ten years of radiosonde profiles at 11 coastal sites (Nygård et al. 2013a) in 105 Antarctica. Additionally, Roberts et al. (2010) documented that specific humidity above $900 \mathrm{hPa}$ 106 tends to be higher than surface values over the northeastern Pacific Ocean in MERRA. Humidity 107 inversions have also been observed over the Sichuan Basin (Jiang et al., 2012), the Tibetan 108 Plateau (Liu et al., 2002), and associated with a radiative fog event in Nanjing, China (Liu et al., 109 2010). Humidity inversions outside of the polar regions may go by various other names. For 110 instance, Kloesel and Albrecht (1989) called them " $q$-reversals.” They also may be found when 111 looking at other phenomena, such as stratospheric air intrusions (Di Giralamo, 2009).

112 Such specific humidity inversions might have a radiative impact. Devasthale et al.

113 (2011) implied that humidity inversions in the Arctic would impact longwave radiation 
114 especially in winter since the inversion contributes as much as $50 \%$ to the total column

115 precipitable water. Other radiative impacts may be associated with their effect on clouds. Sedlar 116 and Tjernström (2009), Solomon et al. (2011), and Sedlar et al. (2011) documented instances of

117 humidity inversions topping Arctic stratus in the summer, and Paluch et al. (1999) gave details of 118 instances of higher free tropospheric specific humidity than in the boundary layer, or in other 119 words, a humidity inversion, over the eastern Equatorial Pacific. All of these suggest that these 120 humidity inversions prevent evaporation from cloud-top entrainment (induced by cloud-top 121 radiative cooling), thus promoting continuity of the boundary layer cloud. Furthermore, such 122 inversions would also impact the temperature-lapse rate feedback of the greenhouse effect, 123 particularly at high latitudes where it is more important (Webb et al., 1993; Curry et al., 1995). 124 Given the possible implications of specific humidity inversions sometimes occurring in 125 the troposphere, what are the temporal and spatial variabilities of such instances? Recently, 126 Devasthale et al. (2011) produced a clear-sky climatology in the Arctic based on Atmospheric 127 Infrared Sounder (AIRS) profiles. They found that Arctic humidity inversions were more 128 prevalent in winter but strongest in summer. Our strategy is to do something similar but instead 129 look at the all-sky climatology globally by using reanalyses. Similar work was done by Nygård 130 et al. (2013b) for the Arctic and by Nygård et al. (2013a) in the Antarctic using radiosonde 131 observations. However, by using radiosonde observations only, the results are rather localized, 132 especially since these are only available regularly over land. A truly regional, and even global, 133 perspective can only be reached by using reanalyses in which radiosonde data is assimilated.

134 The reanalyses included here are two older generation reanalyses [the European Centre for 135 Medium-Range Weather Forecasts (ECMWF) 40-year reanalysis (ERA-40) and the National 136 Oceanic and Atmospheric Administration (NOAA) National Centers for Environmental 
137 Prediction (NCEP) reanalysis] and three current generation reanalyses (NASA MERRA, NOAA 138 CFSR, and ECMWF ERA-Interim).

139 Recent studies have shown that some or all of these reanalyses have erroneous

140 realizations of the low-level thermodynamics. For instance, Serreze et al. (2012) recently found

141 that NCEP-1 (the predecessor to NCEP-2), ERA-40, the Japanese 25-year reanalysis (JRA-25),

142 MERRA, CFSR, and ERA-Interim were biased warm and moist on average in comparison to

143 radiosonde observations at nine locations across the Arctic Basin, thus preventing the realization

144 of persistent temperature and humidity inversions. Similar warm and moist near-surface biases

145 were found by Jakobson et al. (2012) in comparisons of tethersoundings taken at the drifting ice

146 station Tara with the latest generation of reanalyses (MERRA, CFSR, ERA-Interim, and the

147 Japanese Meteorological Agency Climate Data Assimilation). A warm near-surface bias was

148 also found by Tjernström and Graversen (2009) in ERA-40 in comparison to soundings taken

149 during the Surface Heat Balance of the Arctic (SHEBA) field experiment. de Boer et al. (2013)

150 showed that such errors could be caused by errors in cloud occurrence and location in the models

151 used to generate the reanalyses. Still, Fig. 3 shows the relative frequency of specific humidity

152 inversions in the five reanalyses compared here, including two different versions of ERA-40

153 (ERA-40m and ERA-40p) which are defined below. Most reanalyses have humidity inversions

154 in large portions of both polar regions in $100 \%$ (the light pink contour) of January means in the

155 Northern Hemisphere and of July means in the Southern Hemisphere. This suggests that the

156 humidity inversions in the reanalyses are strong and/or persistent enough to withstand the

157 monthly averaging during these months.

158 The reanalyses are described in the next section, and the results are presented in section

159 3. In Section 4, we compare the reanalysis inversions to those in rawinsonde data, and in Section 
160 5, we disucss the possible mechanisms for developing and maintaining such humidity

161 inversions. Conclusions and further discussion are provided in Section 6.

\section{2. Reanalyses}

163 In this study, we use both the monthly mean and 6-hourly values from the second version

164 of the NCEP reanalysis (hereafter, NCEP-2), ERA-40 (including three versions with varying

165 horizontal and vertical resolutions), MERRA, CFSR, and ERA-Interim. A brief description of

166 each reanalysis follows; more description can be found in the included references.

167 2.1. NCEP-2

168 NCEP-2 (also referred to as NCEP-DOE) was developed as a revision of the first 169 reanalysis to correct errors discovered in the processing of the earlier version. NCEP-2 utilizes

170 the same T62 spectral resolution model with 28 vertical layers as in the first version (NCEP-1)

171 with some minor improvements to the model physics and data assimilation (Kanamitsu et al.,

172 2002). Like in NCEP-1, data, which, for upper air, includes conventional sources from

173 rawinsondes, dropsondes, pilot balloons (PIBALs), wind profilers, and aircraft measurements as

174 well as satellite radiances from the Satellite Infrared Spectrometer (SIRS), the High Resolution

175 Infrared Sounder (HIRS), the Vertical Temperature Profile Radiometer (VTPR), and TIROS

176 Operational Vertical Sounder (TOVS) and upper-air winds from geostrationary satellites, were

177 assimilated using the spectral statistical interpolation (SSI) technique (Kalnay et al., 1996).

178 Here, we choose to use NCEP-2, because NCEP-1 had negative specific humidities in

179 some parts of the polar regions. This seems to be one of the errors that has been corrected in

180 NCEP-2. Both the monthly and 6-hourly data downloaded from the mass storage on the

181 supercomputers at National Center for Atmospheric Research (NCAR) are on a regular $2.5^{\circ} \times$

$182 \quad 2.5^{\circ}$ grid with 17 standard pressure levels. 
194 ERA-40m), the data averaged vertically to 23 standard pressure levels but horizontally on the 195 model grid (hereafter ERA-40p), and the data averaged horizontally to a regular horizontal grid 196 of $2.5^{\circ} \times 2.5^{\circ}$ and vertically to 23 standard pressure levels (hereafter ERA-40g). ERA-40m and 197 ERA-40p were downloaded from NCAR’s Research Data Archive (RDA) web site 198 (http://rda.ucar.edu), while ERA-40g was downloaded from the ECMWF website 199 (http://www.ecmwf.int).

\section{2.3. MERRA}

\subsection{ERA-40}

ERA-40 utilized the ECMWF atmospheric model with a spectral resolution of T159 and 60 vertical layers (Uppala et al., 2005). The model included improved parameterizations of deep convection and radiation and a new representation of sea ice (Uppala et al., 2005). Data assimilation was done by a 3D-Var system. Upper air observations from conventional sources were combined with satellite measurements from geostationary satellites, HIRS, the Microwave Sounding Unit (MSU), and the Advanced Microwave Sounding Unit A (AMSU-A) (Uppala et al., 2005). differ in terms of horizontal and vertical grids: the model original resolution both horizontally and vertically $\left(\sim 1.125^{\circ} \times 1.125^{\circ}\right.$ and 60 vertical model sigma layers, hereafter referred to as 
206 incremental analysis update procedure (Bloom et al., 1996) is implemented (Rienecker et al.,

207 2007). In this procedure, assimilation at the 6-h synoptic times is based upon $6 \mathrm{~h}$ of model

208 predictions centered on the synoptic time. The analyzed correction, then, is applied at the

209 previous $6 \mathrm{~h}$, and the model is run for $12 \mathrm{~h}$ (Suarez et al., 2010).

210 MERRA assimilates upper-air data from conventional sources as well as from satellite

211 measurements of upper air winds derived from geostationary satellites and the Moderate

212 Resolution Imaging Spectroradiometer (MODIS), radiances from the Geostationary Operational

213 Environmental Satellites (GOES) sounder, TOVS and Advanced TOVS (ATOVS) instruments,

214 the Atmospheric Infrared Sounder (AIRS), MSU, and AMSU-A (Rienecker et al., 2010).

215 Used here are the three-dimensional analysis fields (inst6_3d_ana_Np) which are

216 provided in the model horizontal resolution $\left(1 / 2^{\circ}\right.$ latitude $\times 2 / 3^{\circ}$ longitude) in both the 6 - $h$

217 temporal resolution and the monthly means. These data were downloaded through the Goddard

218 Earth Sciences Data and Information Services Center website (http://data.sci.gsfc.nasa.gov).

\section{2.4. CFSR}

220 CFSR is the latest NCEP reanalysis that utilizes a fully coupled atmosphere-ocean-sea

221 ice-land model, the Climate Forecast System (CFS) (Saha et al., 2010). The atmospheric

222 component is run at T382 spectral resolution with 64 vertical layers, while the ocean component

223 is run at a horizontal resolution that varies between $1 / 4^{\circ}$ and $1 / 2^{\circ}$ latitude $\times 1 / 2^{\circ}$ longitude with

22440 layers in the vertical of which the uppermost is $10 \mathrm{~m}$ thick. Similar upper air data to that of

225 the other reanalyses plus radiances from GOES, AIRS, Advanced Microwave Sounding

226 Radiometer-Earth Observing System (AMSR-E), Infrared Atmospheric Sounding Interferometer

227 (IASI), and Microwave Humidity Sounder (MHS) and radio occultation from the Challenging 
Minisatellite Payload (CHAMP) and the Constellation Observing System for Meteorology,

229 Ionosphere, and Climate (COSMIC) are ingested into the CFSR.

Used here are the 6-hourly and monthly mean profiles gridded at $0.5^{\circ}$ lat/lon on 37

231 pressure levels downloaded from NOAA/National Climatic Data Center’s (NCDC) National

232 Operational Model Archive and Distribution System (NOMADS) website

233 (http://nomads.ncdc.noaa.gov).

\section{2.5. ERA-Interim}

ERA-Interim is the newest ECMWF reanalysis. The model used to produce ERA-

236 Interim has a higher horizontal resolution of T255 and improved model physics from ERA-

237 40. Instead of the 3D-Var assimilation used for ERA-40, ERA-Interim uses a 12-h 4D-Var

238 assimilation system with improvements to the handling of data biases and of the background

239 error constraint (Simmons et al., 2006; Dee et al., 2011). ERA-Interim uses the same data from

240 ERA-40 plus clear-sky radiances from Meteosat-2, Global Ozone Monitoring Experiment

241 (GOME) ozone profiles, CHAMP and COSMIC radio occultation (RO) measurements, the

242 Gravity Recovery and Climate Experiment (GRACE), reprocessed ocean wave height data from

243 ERS-1 and 2, and upper-level winds from Meteosat-2 (Simmons et al., 2006).

$244 \quad$ Used here are the 6-hourly and monthly mean analyses that have been interpolated to 37

245 pressure levels at the model horizontal resolution of $\sim 0.70^{\circ} \times 0.70^{\circ}$. These data were

246 downloaded from the NCAR RDA web site (http://rda.ucar.edu).

\section{3. The specific humidity inversion climatology in the reanalyses}

To better understand the characteristics of humidity inversions, we define a humidity

249 inversion strength QIS. For the vertical column of specific humidity in each grid box of a

250 particular reanalysis, the pressure at the bottom of the lowest inversion layer above which 
251 humidity begins to increase with height is $p_{\max }$, and the pressure at the top of that layer is $p_{\min }$.

252 Then,

253 QIS $=\frac{q\left(p_{\min }\right)-q\left(p_{\max }\right)}{\left|p_{\min }-p_{\max }\right|}$

254 where $q\left(p_{\min }\right)$ and $q\left(p_{\max }\right)$ are the specific humidities (in $\mathrm{g} \mathrm{kg}^{-1}$ ) at the top and bottom of the

255 inversion respectively. Thus if the pressures are given in hPa, QIS has units of $\mathrm{g} \mathrm{kg}^{-1} \mathrm{hPa}^{-1}$.

256 For the mean January profile in the Northern Hemisphere (in the middle of the season

257 with the deepest and largest area of positive $\Delta q$ over the Arctic), Fig. 4 shows that all reanalyses

258 have humidity inversions in most of the areas poleward of $60^{\circ} \mathrm{N}$ as well as over much of mid-

259 latitude Eurasia. NCEP-2 and MERRA also have inversions extending down over the North

260 American continent east of the Rockies. Another area of inversions occurs along $\sim 15^{\circ} \mathrm{N}$ from

261 the northeastern Atlantic subtropical stratus region eastward into the southern Sahara and

262 Sahel. MERRA additionally has some humidity inversions in January over the northeastern

263 Pacific stratus region. The geographical extent varies between the different reanalyses in these

264 regions. NCEP-2 has the smallest extent over the northeast Atlantic and the Sahara, whereas

265 MERRA and CFSR have the most. There is also a difference between ERA-40m and ERA-40p

266 in that humidity inversions cover less area over the northeast Atlantic and the Sahara in the latter.

267 Even poleward of this, humidity inversions cover less area over the mid-latitudes in ERA-40p

268 than in ERA-40m. The extent of humidity inversions in ERA-40g is very similar to ERA-40p

269 (not shown).

$270 \quad$ Humidity inversions are weakest $\left(<0.0025 \mathrm{~g} \mathrm{~kg}^{-1} \mathrm{hPa}^{-1}\right)$ over the Arctic and stronger over

271 the subtropics (Fig. 4). The strongest inversions appear in NCEP-2 over the eastern Sahara (Fig.

272 4a) and in MERRA over the northeast Atlantic (Fig. 4j). The inversion bases over most of the

273 Arctic and mid-latitudes are low to the ground (> $900 \mathrm{hPa}$ except over high terrain) in all 
274 reanalyses. They are mostly higher $\left(p_{\max }<900 \mathrm{hPa}\right.$ ) in both ERA-40m, MERRA, and CFSR

275 around $\sim 15^{\circ} \mathrm{N}$ over the Sahara and the Northeast Atlantic (Fig. 4e,h,k), whereas the bases are 276 still generally low (> $900 \mathrm{hPa}$ ) in these regions in NCEP-2, ERA-40p, and ERA-Interim (Fig.

277 4b,n). The inversions are generally thicker (> $150 \mathrm{hPa}$ ) in NCEP-2, ERA-40p, and CFSR (Fig.

278 4c,f,l) and thinner ( $<150 \mathrm{hPa})$ in ERA-40m, MERRA and ERA-Interim over the Arctic.

279 The quantities based on the mean July profile in the Southern Hemisphere are shown in

280 Fig. 5. As in the Northern Hemisphere winter, NCEP-2, ERA-40m, MERRA, CFSR, and ERA-

281 Interim have mean inversions over most of Antarctica and some of the nearby ocean (Fig.

$2825 \mathrm{a}, \mathrm{d}, \mathrm{j}, \mathrm{m}, \mathrm{p})$. MERRA also produces more inversions further out over the Southern Ocean than 283 any of the other reanalyses (Fig. 5j). On the other hand, humidity inversions are lost over most 284 of the Antarctic continent in ERA-40p, restricted to mainly the coast and nearby oceans (Fig. 285 5g). ERA-40g looks very similar to ERA-40p (not shown). Additionally, there are mean 286 inversions over at least part of the subtropical stratus regions over both the southeast Atlantic and 287 Pacific in NCEP-2, ERA-40m, MERRA, CFSR, and ERA-Interim (Fig. 5a,d,j,m,p). On the 288 other hand, the humidity inversions have almost been lost over the subtropical stratus regions in 289 ERA-40p, being limited to a very small area over the southeastern Atlantic stratus region (Fig. 290 5g). This is the same in ERA-40g (not shown). Interestingly, ERA-Interim with its higher 291 horizontal resolution also has a limited amount of humidity inversions over the Southern 292 Hemisphere subtropical stratus regions (Fig. 5p).

293 QIS is smallest over the polar region and higher over the subtropical stratus regions in all 294 reanalyses (Fig. 5a,d,g,j,m,p). QIS is also higher in MERRA over the Southern Ocean (Fig. 5j). 295 In fact, the highest QIS (>0.01 $\left.\mathrm{g} \mathrm{kg}^{-1} \mathrm{hPa}^{-1}\right)$ is from MERRA over the southeast Pacific and the 296 Southern Ocean. In the Antarctic, the polar inversion bases are low to the ground following the 
terrain to higher altitudes where there are humidity inversions in the interior of the continent

298 (Fig. 5b,e,h,k,n,q). In the subtropical stratus regions, the inversions are generally the lowest near 299 the coast $\left(p_{\max }>900 \mathrm{hPa}\right)$ and are lifted higher $\left(600<p_{\max }<900 \mathrm{hPa}\right)$ away from the coast in 300 NCEP-2, MERRA, and CFSR (Fig. 5b,h,n). Over the Antarctic, the humidity inversions are 301 thicker in NCEP-2 than in ERA-40m, MERRA, CFSR, and ERA-Interim (Fig. 5c,f,l,o,r). Over 302 the subtropical stratus, NCEP-2's inversions are thicker offshore, whereas there is no indication 303 of this in ERA-40m, MERRA, or CFSR (Fig. 5c,f,l,o).

$304 \quad$ Figs. 4 and 5 are based on the humidity inversion in the climatological mean humidity 305 profile. If, however, the humidity inversions are computed from each month’s mean humidity 306 profile, they also appear in varying degrees of frequency in most of the mid-latitudes and along a 307 substantial fraction of a band along $\sim 15^{\circ}$ of both hemispheres in all reanalyses (Fig. 3). The 308 frequency of occurrence in monthly mean humidity inversions is $100 \%$ (the light pink contour) 309 over large fractions of the Arctic in all reanalyses (Fig. 3a,c,e,g,i,k) and of the Antarctic in 310 NCEP-2, ERA-40m, MERRA, CFSR, and ERA-Interim (Fig. 3b,d,h,j,l); humidity inversions are 311 still largely absent from most of the interior of Antarctica in ERA-40p (Fig. 3e,f). Humidity 312 inversion frequency is $>60 \%$ over a large portion of the subtropical stratus regions except in the 313 northeast Pacific (Fig. 3). Because of the low frequency of occurrence in this region, the 314 humidity inversion is averaged out of the climatological mean profile in this region (Fig. 4). 315 Taking the mean of the quantities QIS, inversion base, and inversion thickness derived 316 from each January's mean profile, the correlation in these quantities of NCEP-2 with ERA-40g, 317 MERRA, CFSR, and ERA-Interim in the Northern Hemisphere is shown in Fig. 6. Here, we 318 directly compare ERA-40g with the same resolution NCEP-2 product, whereas the other higher 319 resolution reanalyses are regridded to the same $2.5^{\circ} \times 2.5^{\circ}$ resolution of NCEP-2. Note that 
320 unshaded areas not only indicate areas where there are no humidity inversions but also areas

321 where there is absolutely no variation in that quantity in either NCEP-2 or the other reanalysis or

322 both. Fig. 6 shows that where there is variation in the QIS in both reanalyses, the correlation

323 between the NCEP-2 and this quantity is weak as indicated by the light shading (Fig. 6a,d,g,j).

324 In most areas, the other reanalyses are positively correlated, but there is more negative

325 correlation over the Sahara and northeast Atlantic in all reanalyses. Also, MERRA is more

326 negatively correlated over the mid-latitudes. On the other hand, the reanalyses are very strongly

327 correlated to NCEP-2 in inversion base and thickness as indicated by the darkest shadings,

328 mostly positively although again more negatively over the Sahara and northeast Atlantic (Fig.

329 6b,c,e,f,h,I,k,l). The same is true for the Southern Hemisphere in July (not shown).

$330 \quad$ The annual cycle in polar regional mean statistics are presented in Fig. 7. The top row

331 presents the maximum percent total area possible to be covered by humidity inversions. As

332 expected from Fig. 5, MERRA's inversion covers more area than the other reanalyses (Fig.

$3337 \mathrm{a}, \mathrm{b})$. In fact in boreal winter, almost $100 \%$ of the grids poleward of $60^{\circ} \mathrm{N}$ have inversions in the

334 1981-2000 mean. There is a minimum in all reanalyses in the areal extent in boreal summer

335 (May in ERA-40p and ERA-40g with a secondary minimum in September; June in ERA-40m,

336 MERRA and ERA-Interim; August in NCEP-2; and September in CFSR with a secondary

337 minimum earlier in May). The secondary minimums in all versions of ERA-40, CFSR, and

338 ERA-Interim are due to a slight increase in maximum possible areal extent reported by all of

339 these in mid-summer. Also expected from Fig. 5, the vertical averaging done in ERA-40p and

340 ERA-40g reduces maximum areal extent in these versions, most profoundly in boreal

341 summer. In the Antarctic, the difference between the maximum possible areal extent of the

342 inversion is more noticeable between MERRA and the other reanalyses (Fig. 7b). MERRA has a 
343 minimum extent of $\sim 75 \%$ in December and a maximum of $>95 \%$ in austral winter (July-

344 September). On the other hand, NCEP-2, ERA-40m, ERA-40p, ERA-40g, CFSR, and ERA-

345 Interim have a maximum of only 40\%, 40\%, 22\%, 22\%, 30\%, and 20\%, respectively, in austral 346 winter (Fig. 7b).

347 The remaining quantities reported in Fig. 7 are obtained from taking the regional mean of

348 the quantities that have been averaged for each month over the 20-yr period 1981-2000. In the

349 Arctic, MERRA has the highest QIS than any other reanalysis, but all reanalyses have a

350 maximum in QIS in boreal summer (Fig. 7c). Over the Antarctic, all reanalyses have fairly

351 constant mean inversion strength or a very weak annual cycle in this quantity (Fig. 7d).

352 As can be seen in Fig. 3, Arctic inversion bases from all five reanalyses are low (> 900

$353 \mathrm{hPa}$ ) with very little variation throughout the year (Fig. 7e). Over the Antarctic, MERRA shows

354 a weak annual cycle in base pressure with slightly lower bases in austral summer (December and

355 January) and fairly constant pressures across most other months (Fig. 7f). Base pressures in all

356 versions of ERA-40, CFSR, and ERA-Interim peak in austral spring (November and October,

357 respectively). NCEP-2, on the other hand, has a very strong annual cycle in base pressure with

358 much higher bases in January.

359 The annual cycle in both Arctic and Antarctic inversion thickness is fairly similar in

360 NCEP-2, ERA-40m, MERRA, CFSR, and ERA-Interim with minimum thicknesses in summer

361 and higher thicknesses in winter, but the thicknesses in NCEP-2, ERA-40p, and ERA-40g are

362 higher than in the other three-reanalyses (Fig. 7g,h). This is to be expected considering the lower

363 vertical resolution of these latter products.

364 The monthly mean low cloud amount from the International Satellite Cloud Climatology

365 Project (ISCCP) D2 product (Rossow and Schiffer, 1999; available from 

http://isccp.giss.nasa.gov) is given in the bottommost panels in Fig. 7. In the Arctic (Fig. 7i),

367 low cloud amount is smallest in winter and largest in summer with a maximum in June. This is 368 also the season when humidity inversion strength is largest in this region (Fig. 7c). This suggests 369 that humidity inversion characteristics may be influenced by clouds or vice versa in this region. 370 This will be explored in more detail in Section 5. On the other hand in the Antarctic, the annual 371 cycle in low cloud amount is small (Fig. 7j), coinciding with a similarly small annual cycle in 372 humidity inversion strength (Fig. 7d). A similar figure for the subtropical stratus regions is presented in Fig. 8. MERRA and

374 CFSR generally have larger maximum possible inversion areal extent except for in the northeast 375 Atlantic from June to November, while ERA-Interim generally has the lowest areal extents (Fig. 376 8a-d). On the other hand, NCEP-2 has the highest mean inversion strength in these regions (Fig. 377 8e-h). As deduced from Figs. 3 and 4, the mean inversion bases are lowest from NCEP-2 in all 378 of these regions, whereas those in all versions of ERA-40, MERRA, CFSR, and ERA-Interim are 379 generally about the same (Fig. 8i-l). Also as in Figs. 3 and 4, the reanalysis inversion 380 thicknesses are similar from ERA-40m, MERRA, CFSR, and ERA-Interim, while NCEP-2, 381 ERA-40p, and ERA-40g with reduced vertical resolutions have generally larger thicknesses in all 382 four regions.

The monthly mean ISCCP low cloud amount for these subtropical stratus regions is also 384 presented in the bottommost panels of Fig. 8. ISCCP low cloud amount is maximum in August 385 in the northeast Pacific (Fig. 8q), January in the northeast Atlantic (Fig. 8r), and July in the 386 southeast Pacific and Atlantic (Fig. 8s,t), while the cloud minimum occurs in November, August, 387 and February over the northeast Pacific, northeast Atlantic, and southeast Pacific and Atlantic, 388 respectively (Fig. 8q-t). These cloud fractions seem not to correspond as well to humidity 
inversions characteristics as they do in the Arctic. For instance, the highest maximum possible

390 coverage (Fig. 8a-d) and QIS (Fig. 8e-h) seem to occur when cloud cover is increased but not

391 necessarily when cloud cover is at its maximum (Fig. 3q-t). This also varies from region to

392 region and product to product.

\section{4. Comparison to rawinsonde data}

To verify the veracity of the humidity inversions in the reanalyses presented above, the

395 reanalysis humidity profiles are compared to those of in situ rawinsonde data archived at the

396 NOAA Earth System Research Laboratory (ESRL) (Schwartz and Govett, 1992). These data are

397 also included in the Global Telecommunications System (GTS) that the reanalyses obtain their

398 rawinsonde data from. The data from 1994 to 2001 were downloaded from the website

399 http://www.esrl.noaa.gov/raobs. They have been processed using a hydrostatic error handling

400 procedure to detect inconsistencies between observed temperatures and reported heights. Only

401 data up to $300 \mathrm{hPa}$ are used here. We selected a number of stations based upon whether or not

402 they had a sufficient number of records (i.e., at least 20 days of at least one sounding per day for

403 every month) in the database. From these, we selected nine stations in the Arctic and four in the

404 Antarctic because of our focus on the polar regions plus another six from the mid-latitudes and

405 subtropics and three from the tropics. Table 1 gives the locations of these 22 sites.

An example of the mean rawinsonde humidity profiles for January at the nine Arctic

407 stations is shown in Fig. 9. At all stations except Ausiat, the observations indicate a mean near-

408 surface humidity inversion of varying strength. For the reanalysis profiles, we take those from

409 the 6-h values of the grid box that contains the station location interpolated to the rawinsonde

410 vertical resolution. The reanalysis humidity profiles are generally smaller than the observed

411 profile, whereas ERA-40’s humidity profiles are higher than the observations at two stations 
412 (Scoresbysund and Inuvik). There are inversions in the mean profiles from all reanalyses except

413 NCEP-2 at all locations except Ausiat, while NCEP-2 produces inversions at all stations except

414 Ausiat and Scoresbysund. The humidity profiles are not very different between ERA-40m and

415 ERA-40g except at Barrow and Kotzebue.

$416 \quad$ Histograms of the frequency of inversions at these stations show that inversions occur

417 throughout the year in both the observations and the reanalyses (Fig. 10). The highest observed 418 frequencies (> 80\%) occur at Barrow (Fig. 10c), Alert (Fig. 10e), Eureka (Fig. 10f), Cambridge 419 Bay (Fig. 10h), and Inuvik (Fig. 10i) in the winter and autumn. At these sites plus Kotzebue, 420 there is a prounounced annual cycle with much more frequent inversions in winter than in 421 summer or autumn. At the two Greenland stations (Ausiat and Scoresbysund, Fig. 10a,b), the 422 observed annual cycle is much less pronounced, especially at Scoresbysund. At these sites, the 423 reanalyses produce a larger annual cycle with MERRA, all versions of ERA-40, CFSR, and 424 ERA-Interim overestimating the frequency of occurrence in the winter and autumn and 425 underestimating in the summer and NCEP-2 underestimating all year long. At these Arctic 426 locations, the different versions of ERA-40 are generally consistent.

427 The reanalyses are quite inconsistent over Antarctica (Fig. 11). At Casey (Fig. 11a), 428 ERA-40m, ERA-40p, MERRA, CFSR, and ERA-Interim have a pronounced annual cycle with 429 generally overestimated inversion frequencies throughout the year by MERRA, CFSR, and 430 ERA-Interim and overestimated frequencies only in austral winter by ERA-40m and ERA-40p.

431 On the other hand, NCEP-2 and ERA-40g have a small annual cycle, generally underestimating 432 this. At Amundsen-Scott (Fig. 11b), the reanalyses produce inversions throughout the year, 433 whereas there are practically none observed in austral winter (June-August) and only a few 434 observed during the rest of the year. At Mawson (Fig. 11c), the reanalyses underestimate 
435 inversion frequency throughout the year. ERA-40m, ERA-40p, MERRA, CFSR, and ERA-

436 Interim have a small annual cycle, but NCEP-2 and ERA-40g have a pronounced annual cycle

437 with frequencies approaching those observed from April to September. Finally at Dumont

438 d'Urville (Fig. 11d), all reanalyses have a large annual cycle in inversion frequency. Like at

439 Casey, ERA-40m, ERA-40p, MERRA, CFSR, and ERA-Interim generally overestimate

440 frequencies, while NCEP-2 and ERA-40g generally underestimate. So at the Antarctic coastal

441 sites (Fig.11a,c,d), ERA-40g is more consistent with NCEP-2 with the same horizontal resolution

442 than with ERA-40m and ERA-40p at the original model resolution.

443 At the six mid-latitude sites (see Table 1), observed humidity inversions at Legionowo,

444 Durban, and Macquarie Island (Fig. 12a,c,f) do not have a pronounced annual cycle in inversion

445 frequency. At Macquarie Island (Fig. 12f), the reanalyses do not have a strong annual cycle in

446 humidity inversion frequency, while they produce a pronounced annual cycle with maxima in

447 winter at Legionowo and Durban (in January and December and in June, respectively, Fig.

448 12a,c). At the other stations, there is a clear annual cycle in the observations (Fig. 12b,d,e)

449 which all these reanalyses capture at San Clemente Island and Nashville (Fig. 12d,e). At Wuhan

450 (Fig. 12b) though, there is a more pronounced annual cycle in humidity inversion frequency with

451 the reanalyses generally overestimating throughout, less so in summer (July and August). At San

452 Clemente Island underneath the Northeast Pacific stratus deck, the season of highest reanalysis

453 inversion frequency coincides with the season in which the subtropical stratus is at its strongest

454 (Klein and Hartmann, 1993 and Fig. 7q).

455 Some of the differences between the observed annual cycle and those in the reanalyses

456 can also be seen in the diurnal cycle. Fig. 13 presents some examples of the frequencies in the

457 periods from 18:00-6:00 LT (left) and 6:00-18:00 LT (right) for four stations (Eureka, Durban, 
458 Nashville, and Hilo). At Eureka (Fig. 13a,b) and Nashville (Fig. 13e,f), all or most of the

459 observed frequency occurs in the 6:00-18:00 LT period throughout the year, whereas the

460 reanalyses distribute the frequency equally between the two periods. The same is also true at

461 Resolute (not shown). At Durban, the frequency does not change much with season, with the

462 reanalyses generally underestimating frequencies in both time periods. Finally, Hilo is an

463 example where the reanalyses are consistent with the observed even distribution of humidity

464 inversions throughout the day (Fig. 13g,h).

465 A final test on the accuracy of the humidity inversion frequencies in the reanalyses is

466 shown in Table 2. All reanalyses have true positives, i.e., when the reanalysis correctly has a

467 specific humidity inversion, in $38-52 \%$ of the total number of corresponding times with

468 observations. True negatives, i.e., when the reanalyses and rawinsondes both do not have

469 specific humidity inversions, occur $25-30 \%$ of these occurrences. So, ERA-40g, ERA-40m,

470 MERRA, CFSR, and ERA-Interim are correct in having or not having a specific humidity

471 inversion in their profiles $\sim 75 \%$ of the time, while NCEP-2 is correct a little less frequently. For

472 the remaining percentage, the reanalyses either have a humidity inversion when it should not

473 (false positives) or do not have one when it should (false negatives). The split between these

474 depends on the reanalysis. MERRA has nearly equal frequencies of false positives and

475 negatives, while NCEP-2, ERA-40, CFSR, and ERA-Interim have more false negatives than

476 positives. Furthermore, the vertical and horizontal averaging in ERA-40g has the effect of

477 increasing the frequency of false negatives and decreasing that of false positives slightly.

\section{5. Discussion}

479 Given that humidity inversions are quite frequent in the polar regions and less frequent

480 elsewhere as shown in Section 3, under what conditions are humidity inversion formation 
481 favorable? Temperature inversions, moist air advection, dry air advection, differential humidity

482 advection, large-scale subsidence, condensation in the air and at the surface, and turbulence have

483 all been hypothesized as contributing to the formation or continuance of polar humidity

484 inversions (Nygård et al., 2013a; Curry, 1983). In its tavg3_3d_qdt_Cp dataset, MERRA

485 provides the forecasted moisture tendencies due to dynamics; moist physics; turbulence;

486 chemistry; and analysis, or the adjustment made by the assimilation. These quantities averaged

487 over humidity inversions for winter and summer in both the Arctic and Antarctic as a function of

488 the humidity difference across the inversion are presented in Fig. 14. As expected from the

489 location in the lower troposphere, the chemical tendencies are zero. The dynamical (i.e.,

490 advective) tendency provides an overwhelming positive contribution on average to humidity

491 inversions in both seasons and regions particularly as the humidity inversion gets stronger.

492 Moist physics contributes a drying effect to humidity inversions that increases in magnitude with

493 the strength of the humidity inversion. This effect is stronger for the strong inversions in winter

494 than it is in summer in both hemispheres. Turbulence contributes a small moistening that is

495 larger in the summer than in the winter in the Arctic. In the Antarctic, turbulence seems to have

496 very little effect on humidity within inversions. Interestingly, analysis tendencies are low,

497 producing a slight drying, but they have more of an effect in the Arctic summer. This suggests

498 that humidity appears to get too high in humidity inversions in the Arctic, especially in summer.

499 Thus, dynamical, moist physics, and turbulent processes appear to be the most influential

500 on humidity inversions in MERRA. The drying by moist physics would occur from

501 condensation. This can occur within clouds or from cooling the air enough so that water vapor

502 has to be removed, consistent with the Clausius-Clapeyron equation. The latter could occur in

503 temperature inversions, and humidity inversions have long been recognized to be quite often 
associated with temperature inversions in the Arctic (Devasthale et al., 2011; Sedlar et al., 2011;

505 Vihma et al., 2011; Nygård et al., 2013a,b). Furthermore, specific humidity increasing with

506 height would be consistent with the Clausius-Clapeyron equation within an increasing

507 temperature profile (Nygård et al., 2013b) if the relative humidity is 100\% with respect to ice.

508 This is often the case near-surface in the Arctic (Andreas et al., 2002). Temperature inversions

509 are slightly more frequent in Arctic winter (Serreze et al., 1992, 1995), and this is the season

510 when the inversions are most prevalent (Fig. 7). In MERRA, humidity inversions are more

511 prevalent when a temperature inversion is present (not shown). Fig. 15 shows the reanalysis

512 humidity inversion strength as given by the humidity difference across the inversion as a

513 function of the potential temperature difference across the humidity inversion in both polar

514 regions. For most reanalyses, the humidity inversion is stronger when there is also a temperature

515 inversion and as the temperature inversion strengthens. CFSR also has some very strong

516 humidity inversions for unstable conditions that can even exceed the strongest humidity

517 inversions for strongly stable conditions. This tends to occur over the oceans and in summer of

518 both polar regions, suggesting that CFSR may have an even higher low-level moist bias than the

519 other reanalyses.

520 Humidity inversions have also been recognized to be often coincident with clouds (Curry,

521 1986; Devasthale et al, 2011; Sedlar et al., 2011; Solomon et al., 2011). The annual cycle in

522 monthly mean ISCCP low cloud amount is more pronounced in the Arctic (Fig. 7i) with some of

523 the largest cloud amounts being in summer when humidity inversion strength is at its peak (Fig.

524 7c). In contrast in the Antarctic, the annual cycle in low cloud amount (Fig. 7j) and humidity

525 inversion strength (Fig. 7d) are both correspondingly small. An example of a humidity inversion

526 associated with a cloud deck was given by Solomon et al. (2011) at Barrow, Alaska where the 
527 cloud top was situated in the middle of a humidity inversion in both the observations and a large

528 eddy simulation. Similar conditions were also documented by Sedlar and Tjernström (2009) and

529 Sedlar et al. (2011). In MERRA for 1994-2001 for instances of humidity inversions coinciding

530 with a cloud over the Arctic when the surface pressure is above $1000 \mathrm{hPa}$ (poleward of $60^{\circ} \mathrm{N}$ ),

531 the median cloud top (912.5 hPa) lies between the humidity inversion bottom (975.0 hPa) and

532 top (900.0 hPa) in winter (December-February). This is also true in summer (June-August) with

533 the three values being 887.5, 925.0, and $875.0 \mathrm{hPa}$, respectively.

534 Cloud-top humidity inversions that were reported by Sedlar and Tjernström (2009),

535 Solomon et al. (2011), and Sedlar et al. (2011) were also coincident with a temperature

536 inversion. Temperature inversions are indeed prevalent throughout the Arctic (Sverdrup, 1933;

537 Kahl, 1990; Serreze et al., 1992), and humidity inversions are usually coincident with thermal

538 inversions in both polar regions (not shown). Temperature inversions are prevalent throughout

539 the year in the Arctic. However, surface-based inversions were found to be slightly more

540 prevalent in winter and above-surface inversions more prevalent in summer during the Surface

541 Heat Budget in the Arctic (SHEBA) experiment (Tjernström and Graversen, 2009). Polar

542 humidity inversions may also follow this pattern. For example in MERRA during the winters of

543 1994-2001, the median humidity inversion top is lower when there is no cloud present (925.0

$544 \mathrm{hPa}$ ) than when cloud is present $(900.0 \mathrm{hPa})$ over the low-elevation Arctic (when the surface lies

545 below $1000 \mathrm{hPa}$ poleward of $60^{\circ} \mathrm{N}$ ). This is also true over the Southern Ocean (poleward of

$54645^{\circ} \mathrm{S}$ ) with the corresponding values being 825.0 and $750.0 \mathrm{hPa}$, respectively. These results

547 suggest that the humidity inversions tend to be closer to the surface when clouds are less frequent 548 in winter. 
Thus, there appears to be two different humidity inversion regimes in the polar

550 regions. The first is surface-based humidity inversions tied to surface-based temperature

551 inversions. As the surface cools in the development of a surface temperature inversion, the

552 humidity has to decrease adiabatically, because the air cannot hold as much water vapor as it

553 cools (Devasthale et al., 2011). This type of humidity inversion would be more prevalent in the

554 winter because of the prevalence of temperature inversions from the radiative cooling at the

555 surface during the polar night. As clouds become more prevalent going into the summer melt

556 season, a second regime in which humidity inversions capping clouds becomes more

557 dominant. These are also coincidental with temperature inversions near the cloud

558 top. Vowinckel and Orvig (1966) found that near-surface thermal inversions are more prevalent

559 in winter when surface radiative cooling is dominant and upper level inversions are more

560 prevalent in summer when clouds are more prevalent. However, cloud-topped temperature

561 inversions are not necessarily absent from winter. Tjernström and Graversen (2009) found that,

562 during SHEBA, about half of winter temperature inversions were surface-based with the

563 remaining similar to the summer elevated inversions but at a lower height. These winter

564 inversions rapidly moved between these two regimes.

$565 \quad$ For cloud-topped humidity inversions, Solomon et al. (2011) found from large eddy

566 simulations that the downward flux of humidity inferred from the humidity inversion helps

567 maintain stratus by keeping the cloud top air saturated even in the presence of

568 entrainment. Downward moisture flux is also associated with surface-based inversions. This

569 may explain the high frequency of hoarfrost, fog, and "diamond dust" observed in the Arctic

570 (Sverdrup, 1933; Robinson and Ludwig, 1966; Andreas et al., 2002). Curry (1983) found that 
571 falling frozen precipitation aids in the formation of humidity inversions by drying out the air as it 572 falls.

573 Moist air advection, dry air advection, or differential humidity advection have been

574 hypothesized as contributing to the formation or maintenance of humidity inversions (Nygård et 575 al., 2013a). Devasthale et al. (2011) hypothesized that the increased stability of the temperature 576 inversion would further focus moist air advection to the top or near the top of the 577 inversion. Nygård et al. (2013a) suggested that differential humidity advection, i.e., moist air 578 advection at or near the top of the inversion versus dry air advection, may be important. An 579 example of the vertical profiles of the horizontal advective humidity fluxes $\left(-\left.u \Delta q\right|_{x}\right.$ for the zonal 580 direction, thick red lines, and $-\left.v \Delta q\right|_{y}$ for the meridional direction, thick blue lines, where $u$ and $v$ 581 are the horizontal wind speeds in the respective directions and $\left.\Delta q\right|_{x}$ and $\left.\Delta q\right|_{y}$ are the horizontal 582 humidity differences in those respective directions) from MERRA is given in Fig. 16 for five of 583 the Arctic locations in Table 1. The mean humidity inversion bottom (solid red line across) and 584 top (dashed red line across) at each site are also indicated in Fig. 16. Moist air advection at or 585 near the inversion top would be indicated by a positive advective flux there, and this is evident 586 at several locations (in zonal flux at Scoresbysund, Fig. 16a; in zonal flux at Barrow, Fig. 16b; in 587 both fluxes at Kotzebue, Fig. 16c; and in meridional flux at Cambridge Bay, Fig. 16e).

588 However, the highest meridional moist air advection occurs at the bottom of the mean humidity 589 advection at Eureka in January (Fig. 16d) opposite to the dry air advection required by Nygård et 590 al. (2013a). In July, there are increases in zonal humidity advection from negative to near-zero 591 or positive across the humidity inversion only occurring at two locations (Barrow, Fig. 16g; 592 Kotzebue, Fig. 16h). The moist advection is higher in the meridional direction and tends to 593 decrease across the mean humidity inversion. These results may be affected by the combination 
594 of humidity inversions at multiple layers, so it is inconclusive whether local humidity advection

595 plays as much of a role in humidity inversions as previously believed. However, differential

596 humidity advection may play a larger role in the Antarctic, especially at the coastal locations (not

597 shown). This is not surprising considering the strong dry katabatic winds that often occur there

598 (Nygård et al., 2013a).

599 Local humidity advection may not have as much of a role in humidity inversions, and it

600 may be regional humidity convergence that might be more important, particularly in summer.

601 This can be quantified by the column integrated horizontal humidity flux across a certain latitude

602 like $60^{\circ} \mathrm{N}$ for the Arctic. Groves and Francis (2002), deriving such humidity fluxes from

603 satellite-based moisture profiles combined with NCEP-1 winds, noted a net column-integrated

604 (below $300 \mathrm{hPa}$ ) moisture flux between November and March into the Arctic mostly from the

605 North Atlantic into Siberia and out through the Canadian Archipelago. The highest fluxes,

606 though, occurred in boreal summer. An earlier study by Cullather et al. (2000) found similar

607 summer maximum fluxes into the region using reanalysis data from ERA-40 and NCEP-1. Fig.

60817 shows the mean annual cycle in total column integrated horizontal humidity flux from the

609 MERRA dataset tavg1_2d_int_Nx across $60^{\circ} \mathrm{N}$ and $45^{\circ} \mathrm{S}$. The Arctic annual humidity flux cycle

610 here is comparable to that implied from the difference between regional mean precipitation and

611 evaporation in Cullather and Bosilovich (2011). Most of this flux is due to transient eddies, or

612 cyclones (Tietäväinen and Vihma, 2008; Jakobson and Vihma, 2010). Comparing this with the

613 annual cycle in humidity inversion strength (Fig. 7c,d), the maximum humidity fluxes into the

614 two polar regions correspond to the same months in which humidity inversions are the strongest

615 (Fig. 17). The increased regional humidity fluxes provide more moisture for cloud formation

616 which is also more frequent (Fig. 7i,j). In the Arctic in particular, the increased cloud cover 
617 occurs during the melt season. The increased melt pond and open water coverage during this

618 season is also an additional moisture source to the atmosphere.

619 Humidity inversions elsewhere likely play some different roles than in the polar

620 regions. Similar to surface-based inversions in the Arctic regions, they probably affect the

621 development and propagation of radiation fog events (Liu et al., 2011). Unlike in the Arctic,

622 Paluch et al. (1999) found that radiational cooling is reduced from the top of eastern Equatorial

623 Pacific clouds that were topped by humidity inversions. This is similar to the " $q$-reversals" that

624 Kloesel and Albrecht (1989) found from observations of suppressed convective activity in the

625 Tropics. These “q-reversals” were layers of increased specific humidity above a drier layer right

626 above the top of the atmospheric boundary layer. These layers were hypothesized to have

627 derived from deep convective detrainment. Similarly, the higher specific humidity observed by

628 Paluch et al. (1999) over eastern Equatorial Pacific cloud-topped boundary layers was found to

629 have originated from deep convection over the South American continent (Fuelberg et al.,

630 1999). Table 3 presents the median humidity inversion tops and bottoms in MERRA for

631 inversions coincident with clouds along with the median cloud tops for all four subtropical

632 stratus regions presented in Fig. 7. Over the southeast Pacific and Atlantic, the humidity

633 inversions do lie wholly above the cloud top like the "q-reversals" in Kloesel and Albrecht

634 (1989). However, the cloud tops fall in the middle of the humidity inversions in the northeast

635 Pacific like in the Arctic, and the humidity inversions lie wholly within the cloud in the northeast

636 Atlantic.

637 Some of these contradicting characteristics of the subtropical stratus humidity inversions

638 may be due to the reanalyses likely producing too many inversions outside of the polar

639 regions. For the six mid-latitude sites in Fig. 12, the reanalysis performance varies from location 
640 to location as the reanalyses produce reasonable annual cycles at three sites and unreasonable

641 annual cycles at the other three sites. At one of these sites, San Clemente Island, Table 4

642 presents the frequencies of true and false positives and negatives in the reanalyses for 1994-2001

643 similar to what is presented in Table 2 for the Arctic. Most of the reanalyses correctly have

644 many more true negative occurrences of humidity inversions than of true positive. However as

645 suggested by Fig. 12d, there is a large amount of false positives. The effect of vertical and

646 horizontal averaging is to increase the frequency of true negatives slightly by decreasing that of

647 false positives, while the true positive frequency is reduced by increasing the false negative

648 frequency.

\section{6. Conclusions}

We have documented the occurrence of humidity inversions, or layers in which specific

651 humidity increases with height instead of decreasing, in five reanalyses (NCEP-2, ERA-40,

652 MERRA, CFSR, and ERA-Interim), presenting the climatology of these occurrences and of their

653 characteristics in the form of inversion strength, inversion base, and inversion thickness. In the

654 Arctic, humidity inversions are the most prevalent in boreal winter, while the strongest

655 inversions are in the summer melt season (Fig. 7) similar to what Devasthale et al. (2011) found

656 for clear-sky Atmospheric Infrared Sounder (AIRS) satellite data for the Arctic. We have further

657 shown that these five reanalyses produce humidity inversions in the Antarctic and in some other

658 regions, most notably over the subtropical stratus regions. Even though Serreze et al. (2012)

659 found that reanalyses had difficulty in producing humidity inversions over the Arctic, we find

660 that humidity inversions still appear in 100\% of the January (July) monthly means in a large

661 portion of the north (some of the south) polar region and in excess of $60 \%$ of the January (July)

662 monthly means in most of the subtropical stratus regions of the Northern (Southern) Hemisphere 
663 (Fig. 3). There are some discrepancies between the reanalyses and rawinsonde observations at

664 select sites in the Arctic (Fig. 10), Antarctic (Fig. 11), and mid-latitudes (Fig. 12). Since

665 reanalyses provide data more than twice a day, we were able to compare the diurnal cycle of

666 humidity inversions in the reanalyses to the rawinsonde observations here. Such a comparison

667 reveals that the diurnal cycle is not captured correctly by reanalyses at some sites (Fig. 13).

668 Such discrepancies between reanalysis and rawinsonde observations in the polar regions

669 might be due to a lack of rawinsonde data in these regions to constrain the model profiles. This

670 may be especially true for NCEP-2 for which, as Groves and Francis (2002) pointed out,

671 “moisture retrievals from NOAA’s operational TOVS processing system are not assimilated into

672 the NCEP reanalysis over the Arctic, according to observation counts.” If so, the NCEP-2

673 humidity profiles in this region are actually that of the model and would suffer from the effects

674 of model error. Such model error could arise from the model physics, i.e., the parameterizations

675 of small-scale processes such as boundary layer turbulence and clouds. Furthermore, differences

676 in weighting of the various observations and satellite measurements assimilated may also explain

677 some of the differences in realization of humidity inversions between the reanalyses. Also as

678 seen in the comparison of the three different versions of ERA-40, the horizontal and vertical

679 resolution can impact somewhat how the humidity inversions are realized in a reanalysis. This

680 appears to be most problematic in areas of steep topographic gradients and high topography such

681 as over Antarctica (Figs. 4 and 11).

682 The use of reanalysis here allows for the investigation of the roles of various processes in

683 the production of humidity inversions. MERRA provides humidity tendencies due to various

684 processes including dynamics (i.e., advection), moist physics, turbulence, chemistry, and

685 analysis (i.e., assimilation). Based on the mean tendencies across humidity inversions in the 
686 polar regions, dynamics, turbulence, and moist physics are the most important (Fig. 14).

687 Dynamics and turbulence moisten humidity inversions, while moist physics dries inversions.

688 Moist, dry, and differential advection are a few dynamical processes proposed as being

689 influential in triggering or maintaining humidity inversions (Nygård et al., 2013a). Based on

690 mean profiles of advective fluxes of specific humidity (Fig. 16), it is inconclusive whether local

691 advection plays such a strong role in the Arctic, but regional moisture convergence may be more

692 important. The largest humidity fluxes into both polar regions (Fig. 17) are coincident with the

693 season when humidity inversions are strongest (Fig. 7).

694 Moist physical processes can occur within clouds or from condensation due to cooling air

695 until it gets saturated such as what may happen in temperature inversions. In the polar regions,

696 humidity inversions are indeed more prevalent in the presence of a temperature inversion and

697 becoming stronger as the temperature inversion becomes stronger (Fig. 15). However, the

698 strongest humidity inversions occur in the summer melt season when clouds are the most

699 prevalent (Fig. 7). The median summertime cloud tops are located within humidity inversions,

700 creating a way to prevent the evaporation of cloud water by entrainment from the top (Solomon

701 et al., 2011; Sedlar et al., 2011). This explains why stratus clouds are so prevalent in the polar

702 regions during the summer melt season. In the winter, the humidity inversions tend to be lower,

703 or in other words, surface-based. These humidity inversions are caused by the removal of

704 moisture that is required when the surface is cooled to form a temperature inversion. This may

705 help to explain why the surface is almost always near saturation with respect to ice in the Arctic

706 (Andreas et al., 2002) leading to a high frequency of hoarfrost, fog, and “diamond dust”

707 (Sverdrup 1933; Robinson and Ludwig, 1966; Curry, 1983; Andreas et al., 2002). 
Outside of the polar regions, humidity inversions are still possible but less frequent and

709 weaker (Fig. 8). In some regions, humidity inversions are tied to surface-based temperature

710 inversions playing a role in the production and propagation of radiative fog events (Liu et al.,

711 2011). Elsewhere, humidity inversions exist above clouds similar to what happens in the polar

712 regions but may play different roles there than in the polar regions.

713 The work presented here helps to put previous hypotheses, particularly those made for

714 Arctic humidity inversions, into context. Still, some questions remain. For instance, why do a

715 small amount of humidity inversions in the polar regions still exist even when there is no

716 temperature inversion present? Also, polar humidity inversions are unaffected by the phase of

717 the Southern or Northern Annual Modes (not shown), even though one would expect so given

718 the higher humidity fluxes into the polar regions during positive phases (Tietäväinen and Vihma,

719 2008; Jakobson and Vihma, 2010). Even though the reanalyses tend to form too many humidity

720 inversions outside of the polar regions, they have been observed to form from time to time (e.g.,

721 Liu et al. 2002; Liu et al. 2010; Jiang et al. 2012). Back trajectory analysis of observed events

722 would be extremely helpful here.

723 Reanalyses can be useful in further investigating this phenomenon even though their

724 realization of humidity inversions may be problematic as discussed here and in Serreze et al.

725 (2012). As seen here, averaging tends to wash out humidity inversions. Humidity inversions are

726 the least robust in the climatological means. Also, horizontal resolution is important in not

727 washing out humidity inversions, especially over high terrain. Furthermore, vertical resolution

728 affects the realization of inversion statistics such as location and thickness. Thus, the current

729 generation of reanalyses (MERRA, ERA-Interim, and CFSR) with this higher spatial resolution

730 would be more useful in this regard. If process studies are warranted, MERRA includes a 
731 myriad of additional quantities such as tendencies from dynamics and various parameterized

732 processes and vertical integrals of fluxes which no other reanalysis includes so far.

\section{Acknowledgments}

This work was supported by NASA (NNX09A021G) and DOE (DE-SC0006693). We

735 thank NCAR for providing us access to the NCEP-2, ERA-40, and ERA-Interim data; NCEP, 736 ECMWF, and GMAO for producing and making available the five reanalyses; and ESRL for 737 making available the rawinsonde data. Two anonymous reviewers are thanked for their very 738 helpful comments.

\section{References}

740 Andreas, E. L., Guest, P. S., Persson, P. O. G., Fairall, C. W., Horst, T. W., Moritz, R. E., Semmer, S. R., 2002. Near-surface water vapor over polar sea ice is always near ice saturation. J. Geophys. Res., 107, 8033, doi:10.1029/2000JC000411.

Bloom, S., Takacs, L., da Silva, A., Ledvina, D., 1996. Data assimilation using incremental analysis updates. Mon. Weather. Rev., 124, 1256-1271.

745 Cullather, R. I., Bosilovich, M. G., 2011. The moisture budget of the polar atmosphere in MERRA. J. Climate, 24, 2861-2879.

747 Cullather, R. I., Bromwich, D. H., Serreze, M. C., 2000. The atmospheric hydrologic cycle over the Arctic Basin from reanalyses. Part I: Comparison with observations and previous studies. J. Climate, 13, 923-937.

750 Curry, J. A., 1983. On the formation of continental polar air. J. Atmos. Sci., 40, 2278-2292.

751 Curry, J. A., 1986. Interactions among turbulence, radiation, and microphysics in Arctic stratus 752 clouds. J. Atmos Sci., 43, 90-106.

753 Curry, J. A., Schramm, J. L., Serreze, M. C., Ebert, E. E. 1995. Water vapor feedback over the 
Arctic Ocean. J. Geophys. Res., 100, 14 223-14 229.

755 de Boer, G., Shupe, M. D., Caldwell, P. M., Bauer, S. E., Persson, P. O. G., Boyle, J. S., Kelley,

756

757

758

759

760

761

762

763

764

765

766

767

768

769

770

771

772

773

774

775

776

M., Klein, S. A., Tjernström, M., 2013. Near-surface meteorology during the Arctic Summer Cloud Ocean Study (ASCOS): evaluation of reanalyses and global climate models. Atmos. Chem. Phys. Discuss., 13, 19421-19470.

Dee, D. P., and 35 co-authors, 2011. The ERA-Interim reanalysis: configuration and performance of the data assimilation system. Quart. J. Roy. Meteorol. Soc., 137, 553597.

Devasthale, A., Sedlar, J., Tjernström, M., 2011. Characteristics of water-vapour inversions observed over the Arctic by Atmospheric Infrared Sounder (AIRS) and radiosondes. Atmos. Chem. Phys., 11, 9813-9823.

Di Giralamo, P., Summa, D., Ferreti, R., 2009. Multiparameter Raman lidar measurements for the characterization of a dry stratospheric intrusion event. J. Atmos. Ocean. Tech., 26, 1742-1762.

Fuelberg, H. E., Newell, R. E., Longmore, S. P., Zhu, Y., Westberg, D. J., Browell, E. V., Blake, D. R., Gregory, G. L., Sachse, G. W., 1999. A meteorological overview of the Pacific Exploratory Mission (PEM) Tropics period. J. Geophys. Res., 104, 5585-5622.

Gerding, M., Ritter, C., Müller, M., Neuber, R., 2004. Tropospheric water vapour soundings by lidar at high Arctic latitudes. Atmos. Res., 71, 289-302.

Groves, D. G., Francis, J. A., 2002. Variability of the Arctic atmospheric moisture budget from TOVS satellite data. J. Geophys. Res., 107, 4785, doi:10.1029/2002JD002285.

Jakobson, E., Vihma, T., 2010. Atmospheric moisture budget in the Arctic based on the ERA-40 reanalysis. Int. J. Climatol., 20, 2175-2194. 
Jakobson, E., Vihma, T., Palo, T., Jakobson, L., Keernik, H., Jaagus, J., 2012. Validation of atmospheric reanalyses over the central Arctic Ocean. Geophys. Res. Lett., 39, L10802, doi:10.1029/2012GL051591.

Jiang, X., Li, Y., Zhao, X., Koike, T., 2012. Characteristics of the summertime boundary layer and atmospheric vertical structure over the Sichuan Basin. J. Meteorol. Soc. Japan, 90C, 33-54.

Johnsen, K.-P., and B. Rockel, B., 2001. Validation of a regional weather forecast model with GPS data. Phys. Chem. of the Earth, Part B: Hydrology, Oceans and Atmosphere, 26, 415-419.

Kahl, J. D., 1990. Characteristics of the low-level temperature inversion along the Alaskan Arctic coast. Int. J. Climatol., 10, 537-548.

Kalnay, E., and 21 co-authors, 1996. The NCEP/NCAR 40-year reanalysis project. Bull. Amer. Meteorol. Soc., 77, 437-471.

Kanamitsu, M., Ebisuzaki, W., Woollen, J., Yang, S.-K., Hnilo, J. J., Fiorino, M., G. L. Potter, 2002. NCEP-DOE AMIP-II reanalysis (R-2). Bull. Amer. Meteorol. Soc., 83, 16311643.

Klein, S. A., Hartmann, D. L., 1993. The seasonal cycle of low stratiform clouds. J. Climate, 6, 1587-1606.

Kloesel, K. A., Albrecht, B. A., 1989. Low-level inversions over the Tropical Pacific-Thermodynamic structure of the boundary layer and the above-inversion moisture structure. Mon. Weather Rev., 117, 87-101.

Liu, D., Yang, J., Niu, S., Li, Z., 2010. On the evolution and structure of a radiation fog event in Nanjing. Adv. Atmos. Sci., 28, 223-237. 
Liu, H., Zhang, H., Bian, L., Chen, J., Zhou, M., Xu, X., Li, S., Zhao, Y., 2002. Characteristics of micrometeorology in the surface layer in the Tibetan Plateau. Adv. Atmos. Sci., 19, 74-87.

Nygård, T., Valkonen, T., Vihma, T., 2013a. Antarctic low-tropospheric humidity inversions: 10-yr climatology. J. Climate, 26, 5205-5219.

Nygård, T., Valkonen, T., Vihma, T., 2013b. Characteristics of Arctic low-tropospheric humidity inversions based on radio soundings. Atmos. Chem. Phys. Discuss., 13, 2257522605.

Paluch, I. R., McFarquhar, G., Lenschow, D. H., Zhu, Y., 1999. Marine boundary layers associated with ocean upwelling over the eastern equatorial Pacific Ocean. J. Geophys. Res., 104, 30913-30936.

Peixoto, J. P., A. H. Oort, A. H., 1992. Physics of Climate, Amer. Inst. of Phys., New York.

Rienecker, M. R., and 11 co-authors, 2007. The GEOS-5 Data Assimilation SystemDocumentation on Versions 5.0.1, 5.1.0, and 5.2.0, NASA Tech Rep. NASA/TM-2007104606, Greenbelt, Maryland.

Rienecker, M. R., and 29 co-authors, 2011. MERRA—NASA's Modern-Era Retrospective Analysis for Research and Applications. J. Climate, 24, 3624-3648.

Roberts, J. B., Clayson, C. A., Robertson, F. R., Jackson, D. L., 2010. Predicting near-surface atmospheric variables from Special Sensor Microwave/Imager using neural networks with a first-guess approach. J. Geophys. Res., 115, D19113, doi:10.1029/2009JD013099.

Robinson, E., Ludwig, F. L., 1966. Atmospheric water vapour measurements on the Greenland ice cap, in: Polar Meteorology, WMO Technical Note No. 87. WMO, Geneva, Switzerland, 15-28. 
823 Rossow, W. B., Schiffer, R. A., 1999. Advances in understanding clouds from ISCCP. Bull.

$824 \quad$ Amer. Meteorol. Soc., 80, 2261-2287.

825 Saha, S. ,and 51 co-authors, 2010. The NCEP Climate Forecast System Reanalysis. Bull. Amer.

$826 \quad$ Meteorol. Soc., 91, 1015-1057.

827 Schwartz, B., M. Govett, M., 1992. A Hydrostatically Consistent North American Radiosonde

828 Data Base at the Forecast Systems Laboratory, 1946-Present, NOAA Technical

829 Memorandum ERL FSL-4, College Park, Maryland.

830 Sedlar, J., Tjernström, M., 2009. Stratiform cloud-inversion characterization during the Arctic

831 melt season. Bound.-Layer Meteorol., 132, 455-474.

832 Sedlar, J., M. D. Shupe, and M. Tjernström, 2011: On the relationship between thermodynamic

833 structure and cloud top, and its climate significance in the Arctic. J. Climate, 25, 2374-

8342393.

835 Serreze, M. C., Kahl, J. D., Schnell, R. C., 1992. Low-level temperature inversions of the

836 Eurasian Arctic and comparisons with Soviet drifting station data. J. Climate, 5, 614-

$837 \quad 629$.

838 Serreze, M. C., Rehder, M. C., Barry, R. G., Kahl, J. D., Zaitseva, N. A., 1995. The distribution

839 and transport of atmospheric water vapour over the Arctic basin. International J.

$840 \quad$ Climatol., 15, 709-727.

841 Serreze, M. C., Barry, R. G., Walsh, J. E., 1995. Atmospheric water vapor characteristics at

$842 \quad 70^{\circ}$ N. J. Climate, 8, 719-731.

843 Serreze, M. C., Barrett, A. P., Stroeve, J., 2012. Recent changes in tropospheric water vapor

844 over the Arctic as assessed from radiosondes and atmospheric reanalyses. J. Geophys.

845 Res., 117, D10104, doi:10.1029/2011JD017421. 
846 Simmons, A., Uppala, S., Dee, D., Kobayashi, S., 2006. ERA-Interim: New ECMWF reanalysis

847 from 1989 onwards. ECMWF Newsletter, 110, ECMWF, Reading, U.K., 25-35.

848 Solomon, A., Shupe, M. D., Persson, P. O. G., and Morrison, H., 2011. Moisture and dynamical

849 interactions maintaining decoupled Arctic mixed-phase stratocumulus in the presence of

850 a humidity inversion. Atmos. Chem. Phys., 11, 10127-10148.

851 Suarez, M., and co-authors, 2010. File Specification for MERRA products, NASA/GMAO:

852 Greenbelt, MD, available at

853 http://gmao.gsfc.nasa.gov/research/merra/file_specifications.php.

854 Sverdrup, H. U., 1933. Meteorology: Part I, Discussion in: Sverdrup, H. U. (Ed.). The

855 Norwegian North Polar Expedition with the "Maud” 1918-1925, Scientific

856 Results. Geofysisk Institutt, Bergen, 331 pp.

857 Tietäväinen, H., Vihma, T., 2008. Atmospheric moisture budget over Antarctica and the

858 Southern Ocean based on the ERA-40 reanalysis. Int. J. Climatol., 28, 1977-1995.

859 Tjernström, M., 2005. The summer Arctic boundary layer during the Arctic Ocean Experiment

2001 (AOE-2001). Bound.-Layer Meteorol., 117, 5-36.

861 Tjernström, M., Graversen, R. G., 2009. The vertical structure of the lower Arctic troposphere

862 analysed from observations and the ERA-40 reanalysis. Quart. J. Roy. Meteorol. Soc.,

863 135, 431-443.

864 Tjernström, M., Leck, C., Persson, P. O. G., Jensen, M. L., Oncley, S. P., Targino, A., 2004. The

865 Summertime Arctic Atmosphere, Meteorological Measurements During the Arctic Ocean

866 experiment 2001. Bull. Amer. Meteor. Soc., 85, 1305-1321.

867 Tomasi, C., and 10 Co-Authors, 2006. Characterization of the atmospheric temperature and

868 moisture conditions above Dome C (Antarctica) during austral summer and fall months. 

J. Geophys. Res., 111, D20305, doi:10.1029/2005JD006976.

870

871

872 873

874

875

876

Uppala, S. M., and 45 co-authors, 2005. The ERA-40 reanalysis. Quart. J. Roy. Meteorol. Soc., 131, 2961-3012.

Vihma, T., Kilpeläinen, T., Manninen, M., Sjöblom, A., Jakobson, E., Palo, T., Jaagus, J., Maturilli, M., 2011. Characteristics of temperature and humidity inversions and lowlevel jets over Svalbard fjords in spring. Advances in Meteorol., 2011, doi:10.1155/2011/486807.

Vowinckel, E., Orvig, S., 1966. The inversion over the Polar Ocean, in: Polar Meteorology, WMO Technical Note No. 87. WMO, Geneva, Switzerland, 39-59.

Wagner, D., Ruprecht, E., Simmer, C., 1990. A combination of microwave observations from satellites and an EOF analysis to retrieve vertical humidity profiles over the ocean. J. Appl. Meteor., 29, 1142-1157.

Webb, M. J., Slingo, A., Stephens, G. L., 1993. Seasonal variations of the clear-sky greenhouse effect: the role of changes in atmospheric temperatures and humidities. Clim. Dyn., 9, 117-129.

\section{Figure Captions}

Fig. 1. The zonal mean specific humidity ( $\mathrm{g} \mathrm{kg}^{-1}$ ) from MERRA for 1981-2000. The black areas indicate regions that are below ground.

Fig. 2. Zonal mean difference in specific humidity with height $\Delta q\left(\mathrm{~g} \mathrm{~kg}^{-1}\right)$ averaged over 19812000 for (a) December-February (DJF), (b) March-May (MAM), (c) June-August (JJA), and (d) September-November (SON) from MERRA. This $\Delta q$ is calculated at halfway between each pressure level in MERRA as the difference between pressure levels. Blue shading indicates positive $\Delta q$, and the black shading indicates areas below ground. 
892 Fig. 3. The relative frequency of occurrence (\%) of humidity inversions in the January (for the

893

894

895

896

897

898

899

900

901

902

903

904

905

906

907

908

909

910

911

912

913

Northern Hemisphere, left column) and July (for the Southern Hemisphere, right column)

monthly means in NCEP-2, ERA-40m, ERA-40p, MERRA, CFSR, and ERA-Interim.

The light pink contour represents only 100\% frequency of occurrence.

Fig. 4. Northern Hemisphere specific humidity inversion strength [QIS as defined in Eq. (1), g

$\left.\mathrm{kg}^{-1} \mathrm{hPa}^{-1}\right]$ (left column), inversion base pressure ( $p_{\max }, \mathrm{hPa}$ ) (middle column), and inversion thickness $\left(\left|p_{\min }-p_{\max }\right|, \mathrm{hPa}\right)$ (right column) based on the January climatological mean profiles for 1981-2000 in NCEP-2, ERA-40m, ERA-40p, MERRA, CFSR, and ERA-Interim.

Fig. 5. Same as Fig. 4 except for July in the Southern Hemisphere.

Fig. 6. The correlation in QIS, inversion base, and inversion thickness of NCEP-2 with ERA40g, MERRA, CFSR, and ERA-Interim.

Fig. 7. (a,b) Maximum possible percentage of area covered by humidity inversions based upon the total area of all grids in which humidity inversions are possible every month plus area mean (c,d) inversion strength [QIS, Eq. (1)], (e,f) base pressure, and (g,h) thickness for only the grid cells that have an inversion poleward of $60^{\circ} \mathrm{N}$ (left column) and $45^{\circ} \mathrm{S}$ (right column). Also included is the area-mean low cloud fraction from the International Cloud Climatology Project (ISCCP) product (bottom row).

Fig. 8. Same as Fig. 7 except for the subtropical stratus deck regions in the northeast (NE) Pacific $\left(15^{\circ}-30^{\circ} \mathrm{N}, 110^{\circ}-140^{\circ} \mathrm{W}\right)$ (leftmost column), the NE Atlantic $\left(5^{\circ}-25^{\circ} \mathrm{N}, 20^{\circ}-\right.$ $\left.40^{\circ} \mathrm{W}\right)\left(2^{\text {nd }}\right.$ column $)$, the southeast (SE) Pacific $\left(25^{\circ} \mathrm{S}-0^{\circ}, 80^{\circ}-110^{\circ} \mathrm{W}\right)\left(3^{\text {rd }}\right.$ column $)$, and the SE Atlantic $\left(25^{\circ} \mathrm{S}-0^{\circ}, 5^{\circ} \mathrm{W}-5^{\circ} \mathrm{E}\right)$ (rightmost column). 
914 Fig. 9. Climatological mean January specific humidity profiles for 1994-2001 from rawinsonde observations and NCEP-2, ERA-40m, ERA-40g, MERRA, CFSR, and ERA-Interim at nine stations over the Arctic.

917 Fig. 10. Relative frequency of occurrence of humidity inversions per month for each of the Arctic stations in Fig. 9 in the rawinsonde data (obs.), NCEP-2, ERA-40m, ERA-40p, ERA-40g, MERRA, CFSR, and ERA-Interim.

Fig. 11. Same as Fig. 10 except for the four Antarctic stations.

921 Fig. 12. Same as Fig. 10 except for the six mid-latitude stations.

922 Fig. 13. Same as Fig. 10 except for (a,b) Eureka, (c,d) Durban, (e,f) Nashville, and (g,h) Hilo only split into earlier than 6:00 and later than 18:00 LT (left) and between 6:00 and 18:00

Fig. 14. The mean humidity tendencies due to dynamics (“dynamic”), moist physics (“moist”), LT (right). turbulence (“turbulent”), chemical processes (“chemical”), and assimilation (“analysis”) for $0.05 \mathrm{~g} \mathrm{~kg}^{-1}$ bins of the humidity difference across humidity inversions $(\Delta q)$ in the Arctic (top row, latitudes poleward of $60^{\circ} \mathrm{N}$ ) and Antarctic (bottom row, latitudes poleward of $45^{\circ} \mathrm{S}$ ) in local winter (left column) and summer (right column).

Fig. 15. The mean humidity difference across humidity inversions $(\Delta q)$ in the Arctic (top row, latitudes poleward of $60^{\circ} \mathrm{N}$ ) and Antarctic (bottom row, latitudes poleward of $45^{\circ} \mathrm{S}$ ) for 2-K bins of potential temperature difference across humidity inversions $(\Delta \theta)$ in local winter (left column) and summer (right column).

Fig. 16. Climatological mean January (left column) and July (right column) profiles of advective flux of specific humidity $\left(-\left.u \Delta q\right|_{x}\right.$ for the zonal direction, thick red lines, and $-v$ $\left.\Delta q\right|_{y}$ for the meridional direction, thick blue lines, where $u$ and $v$ are the horizontal wind 
speeds in the respective directions and $\left.\Delta q\right|_{x}$ and $\left.\Delta q\right|_{y}$ are the horizontal humidity

941 dashed red lines, respectively, across.

942 Fig. 17. The 1981-2000 mean annual cycle in MERRA tavg1_2d_int_Nx total column

943 integrated specific humidity flux into the Arctic (across $60^{\circ} \mathrm{N}$ ) and the Antarctic (across

$\left.944 \quad 45^{\circ} \mathrm{S}\right)$.

945

946 
Table 1

948 The rawinsonde sites used in this study.

949

950

\begin{tabular}{ll}
\hline Station name & (Lat., Lon.) \\
\hline
\end{tabular}

951

952

953

954

955

956

957

958

Ausiat, Greenland

$\left(68.7^{\circ} \mathrm{N}, 52.75^{\circ} \mathrm{W}\right)$

Scoresbysund, Greenland $\quad\left(70.5^{\circ} \mathrm{N}, 22^{\circ} \mathrm{W}\right)$

Barrow, Alaska

$\left(71.3^{\circ} \mathrm{N}, 146.8^{\circ} \mathrm{W}\right)$

Kotzebue, Alaska

$\left(66.9^{\circ} \mathrm{N}, 162.6^{\circ} \mathrm{W}\right)$

Alert, Canada

$\left(82.5^{\circ} \mathrm{N}, 62.3^{\circ} \mathrm{W}\right)$

Eureka, Canada

$\left(80^{\circ} \mathrm{N}, 85.9^{\circ} \mathrm{W}\right)$

Resolute, Canada

$\left(74.7^{\circ} \mathrm{N}, 95^{\circ} \mathrm{W}\right)$

959 Cambridge Bay, Canada

$\left(69.1^{\circ} \mathrm{N}, 105.1^{\circ} \mathrm{W}\right)$

960 Inuvik, Canada

$\left(68.3^{\circ} \mathrm{N}, 133.5^{\circ} \mathrm{W}\right)$

961

962

963

964

965

966

967

968

969

970

971

972

973

974

975

976

977

978

979

\section{Antarctica}

Casey, Antarctica

$\left(66.3^{\circ} \mathrm{N}, 110.5^{\circ} \mathrm{E}\right)$

Amundsen-Scott, Antarctica $\left(90^{\circ} \mathrm{S}, 0^{\circ} \mathrm{E}\right)$

Mawson, Antarctica

$\left(68.6^{\circ} \mathrm{S}, 62.9^{\circ} \mathrm{E}\right)$

Dumont d'Urville, Antarctica $\left(66.7^{\circ} \mathrm{S}, 140^{\circ} \mathrm{E}\right)$

980

Mid-latitudes

$$
\text { Legionowo, Poland } \quad\left(52.4^{\circ} \mathrm{N}, 21^{\circ} \mathrm{E}\right)
$$

Wuhan, Hubei, China

$\left(30.6^{\circ} \mathrm{N}, 114.1^{\circ} \mathrm{E}\right)$

Durban, South Africa

$\left(30^{\circ} \mathrm{S}, 31^{\circ} \mathrm{E}\right)$

San Clemente Island, Calif. $\quad\left(32.9^{\circ} \mathrm{N}, 117.2^{\circ} \mathrm{W}\right)$

Nashville, Tennessee

$\left(36.3^{\circ} \mathrm{N}, 86.6^{\circ} \mathrm{W}\right)$

Macquarie Island, Australia $\quad\left(54.5^{\circ} \mathrm{S}, 158.9^{\circ} \mathrm{E}\right)$

Tropics

Vishakhapatnam, India

$\left(17.7^{\circ} \mathrm{N}, 83.3^{\circ} \mathrm{E}\right)$

Hong Kong, China

$\left(22.3^{\circ} \mathrm{N}, 114.2^{\circ} \mathrm{E}\right)$

Hilo, Hawaii

$\left(19.7^{\circ} \mathrm{N}, 155.1^{\circ} \mathrm{W}\right)$ 
Table 2

982 The frequency of true positive and negative (when both the reanalysis and the rawinsonde have 983 or do not have a specific humidity inversion, respectively) and false positive and negative (when 984 the reanalysis has a humidity inversion but the rawinsonde does not or vice versa, repectively) 985 humidity inversion occurrence relative to the rawinsonde observations for all nine Arctic 986 stations.

\begin{tabular}{lcccc}
\hline & $\begin{array}{c}\text { True } \\
\text { positive }\end{array}$ & $\begin{array}{c}\text { True } \\
\text { negative }\end{array}$ & $\begin{array}{c}\text { False } \\
\text { positive }\end{array}$ & $\begin{array}{c}\text { False } \\
\text { negative }\end{array}$ \\
\hline NCEP-2 & $38 \%$ & $30 \%$ & $7 \%$ & $25 \%$ \\
ERA-40g & $43 \%$ & $29 \%$ & $8 \%$ & $20 \%$ \\
ERA-40m & $46 \%$ & $29 \%$ & $8 \%$ & $18 \%$ \\
MERRA & $52 \%$ & $26 \%$ & $11 \%$ & $11 \%$ \\
CFSR & $49 \%$ & $26 \%$ & $11 \%$ & $14 \%$ \\
ERA-Interim $46 \%$ & $28 \%$ & $9 \%$ & $17 \%$ \\
\hline
\end{tabular}

\section{Table 3}

Median humidity inversion bottom and top and cloud top for instances of humidity inversions occurring with clouds over each of the subtropical stratus regions in Figure 7. Winter here in the Northern Hemisphere is December-January and is July-August in the Southern Hemisphere and vice versa for summer.

\begin{tabular}{lrl}
\hline Season & Winter & Summer \\
\hline & NE Pacific & \\
Inversion top & $750.0 \mathrm{hPa}$ & $775.0 \mathrm{hPa}$ \\
Cloud top & $837.5 \mathrm{hPa}$ & $862.5 \mathrm{hPa}$ \\
Inversion bottom & $850.0 \mathrm{hPa}$ & $875.0 \mathrm{hPa}$ \\
& & \\
& NE Atlantic & \\
Inversion top & $775.0 \mathrm{hPa}$ & $750.0 \mathrm{hPa}$ \\
Cloud top & $737.5 \mathrm{hPa}$ & $837.5 \mathrm{hPa}$ \\
Inversion bottom & $850.0 \mathrm{hPa}$ & $850.0 \mathrm{hPa}$ \\
& & \\
& SE Pacific & \\
Inversion top & $750.0 \mathrm{hPa}$ & $725.0 \mathrm{hPa}$ \\
Cloud top & $862.5 \mathrm{hPa}$ & $837.5 \mathrm{hPa}$ \\
Inversion bottom & $825.0 \mathrm{hPa}$ & $775.0 \mathrm{hPa}$ \\
& & \\
& & \\
Inversion top & $800.0 \mathrm{hPa}$ & $775.0 \mathrm{hPa}$ \\
Cloud top & $887.5 \mathrm{hPa}$ & $862.5 \mathrm{hPa}$ \\
Inversion bottom & $875.0 \mathrm{hPa}$ & $850.0 \mathrm{hPa}$ \\
\hline
\end{tabular}

1024

1025 
1026 Table 4

1027 Same as Table 2 except at San Clemente Island.

1028

1029

1030

1031

1032

1033

1034

1035

1036

\begin{tabular}{lcccc}
\hline Product & $\begin{array}{c}\text { True } \\
\text { positive }\end{array}$ & $\begin{array}{c}\text { True } \\
\text { negative }\end{array}$ & $\begin{array}{c}\text { False } \\
\text { positive }\end{array}$ & $\begin{array}{c}\text { False } \\
\text { negative }\end{array}$ \\
\hline NCEP-2 & $3 \%$ & $64 \%$ & $28 \%$ & $6 \%$ \\
ERA-40g & $2 \%$ & $76 \%$ & $16 \%$ & $6 \%$ \\
ERA-40m & $3 \%$ & $72 \%$ & $20 \%$ & $5 \%$ \\
MERRA & $4 \%$ & $55 \%$ & $37 \%$ & $4 \%$ \\
CFSR & $4 \%$ & $58 \%$ & $34 \%$ & $4 \%$ \\
ERA-Interim & $2 \%$ & $74 \%$ & $18 \%$ & $6 \%$ \\
\hline
\end{tabular}

1037 


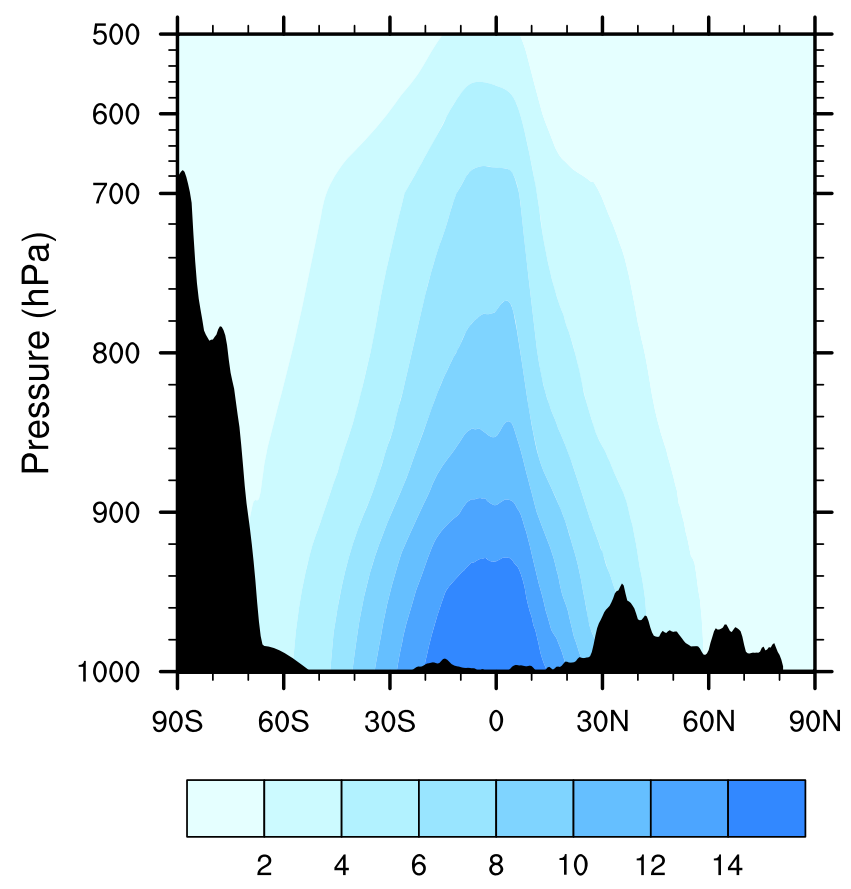

Fig. 1. The zonal mean specific humidity $\left(\mathrm{g} \mathrm{kg}^{-1}\right)$ from MERRA for 1981-2000. The black areas indicate regions that are below ground. 


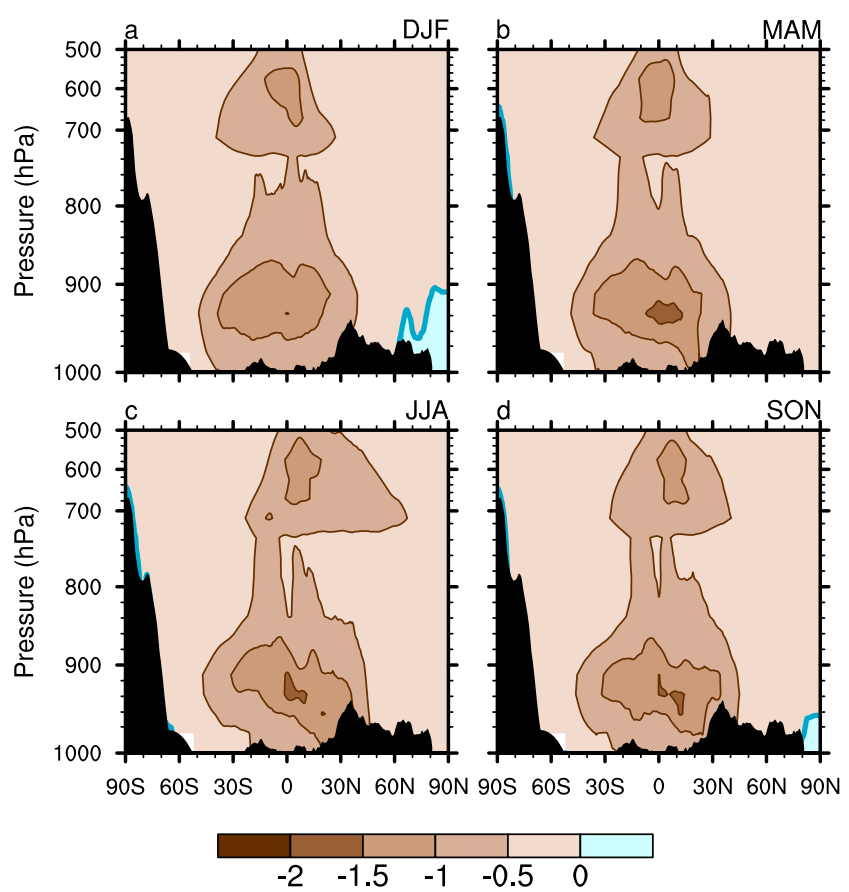

Fig. 2. Zonal mean difference in specific humidity with height $\Delta q\left(\mathrm{~g} \mathrm{~kg}^{-1}\right)$ averaged over 19812000 for (a) December-February (DJF), (b) March-May (MAM), (c) June-August (JJA), and (d) September-November (SON) from MERRA. This $\Delta q$ is calculated at halfway between each pressure level in MERRA as the difference between pressure levels. Blue shading indicates positive $\Delta q$, and the black shading indicates areas below ground. 

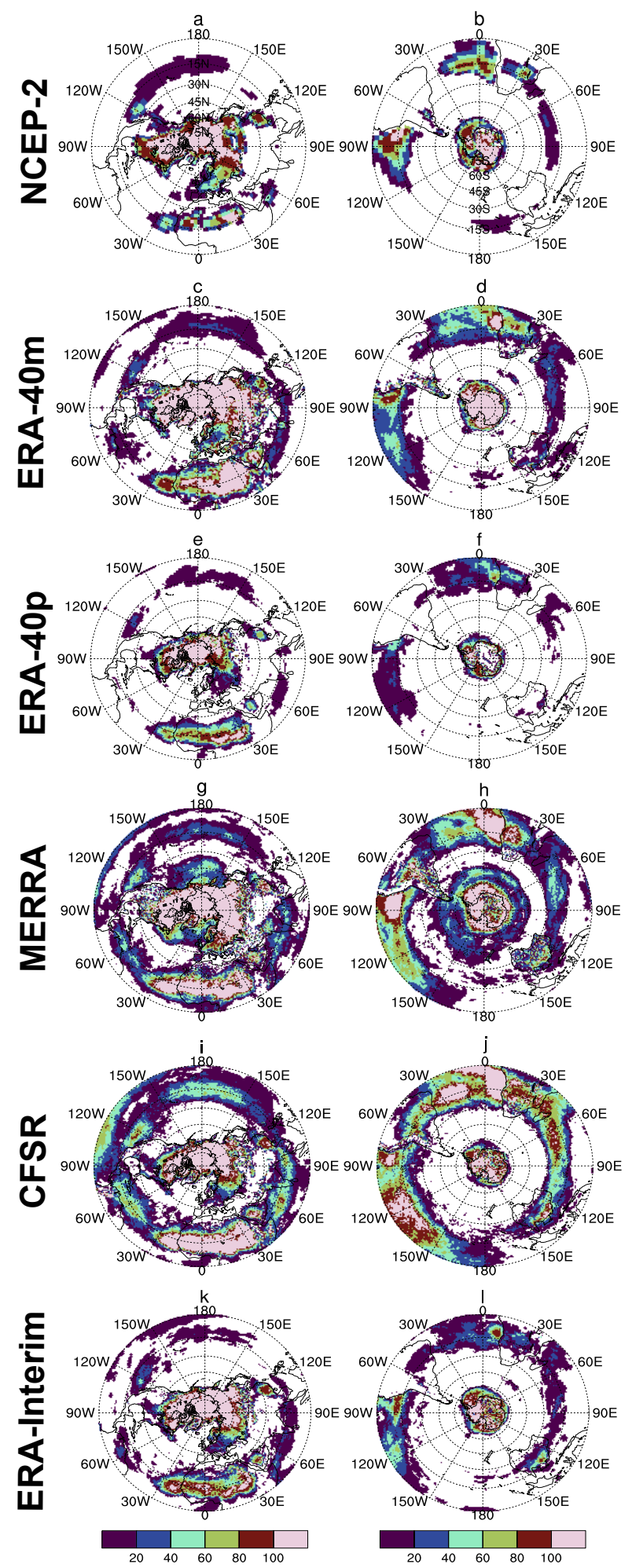

Fig. 3. The relative frequency of occurrence (\%) of humidity inversions in the January (for the Northern Hemisphere, left column) and July (for the Southern Hemisphere, right column) monthly means in NCEP-2, ERA-40m, ERA-40p, MERRA, CFSR, and ERA-Interim. The light pink contour represents only $100 \%$ frequency of occurrence. 


\section{QIS $\left(\mathrm{g} \mathrm{kg}^{-1} \mathrm{hPa}^{-1}\right) \quad$ Inversion base $(\mathrm{hPa})$ Inversion thickness $(\mathrm{hPa})$}
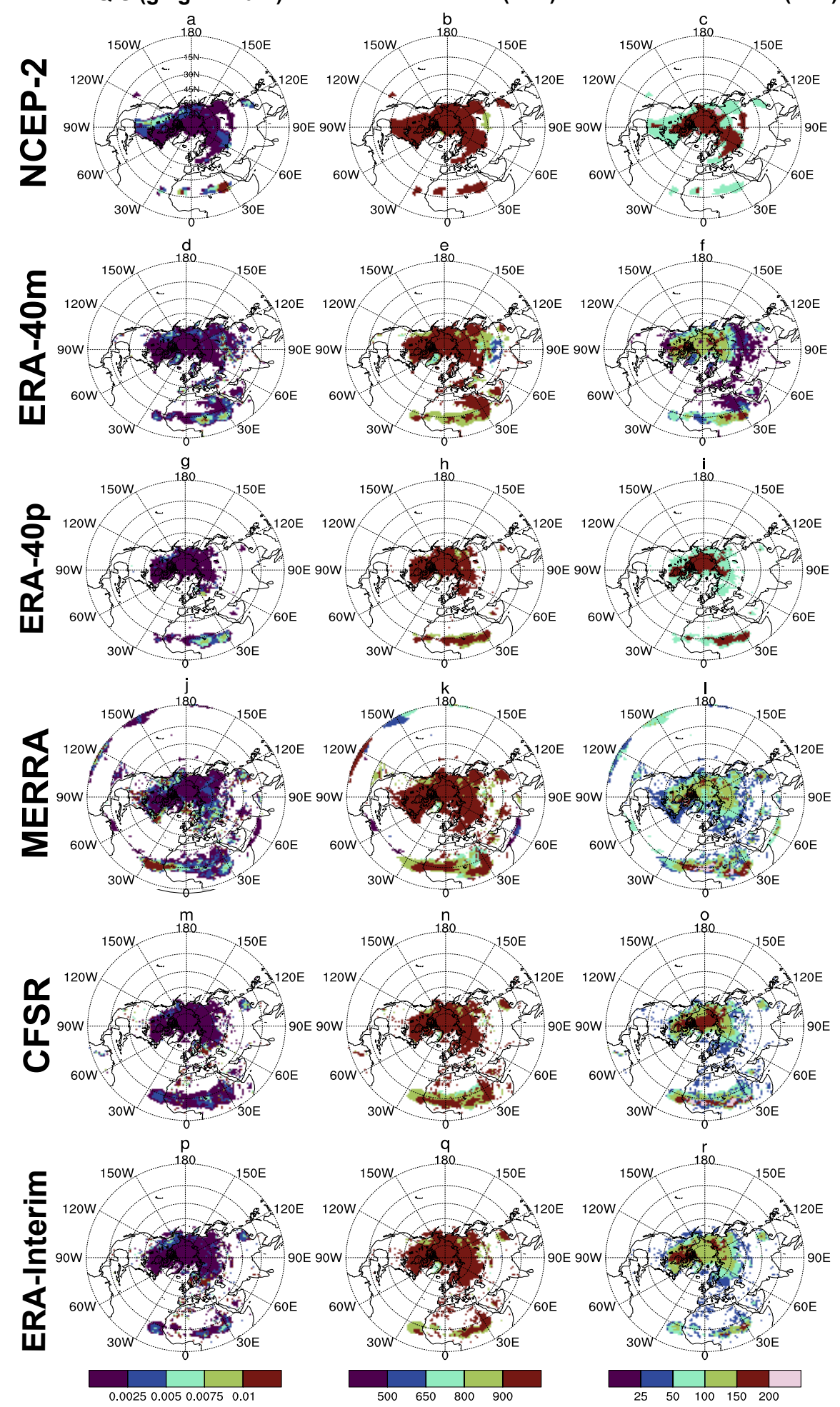

Fig. 4. Northern Hemisphere specific humidity inversion strength [QIS as defined in Eq. (1), g $\left.\mathrm{kg}^{-1} \mathrm{hPa}^{-1}\right]$ (left column), inversion base pressure ( $p_{\max }, \mathrm{hPa}$ ) (middle column), and inversion thickness $\left(\left|p_{\min }-p_{\max }\right|, \mathrm{hPa}\right)$ (right column) based on the January climatological mean profiles for 1981-2000 in NCEP-2, ERA-40m, ERA-40p, MERRA, CFSR, and ERA-Interim. 

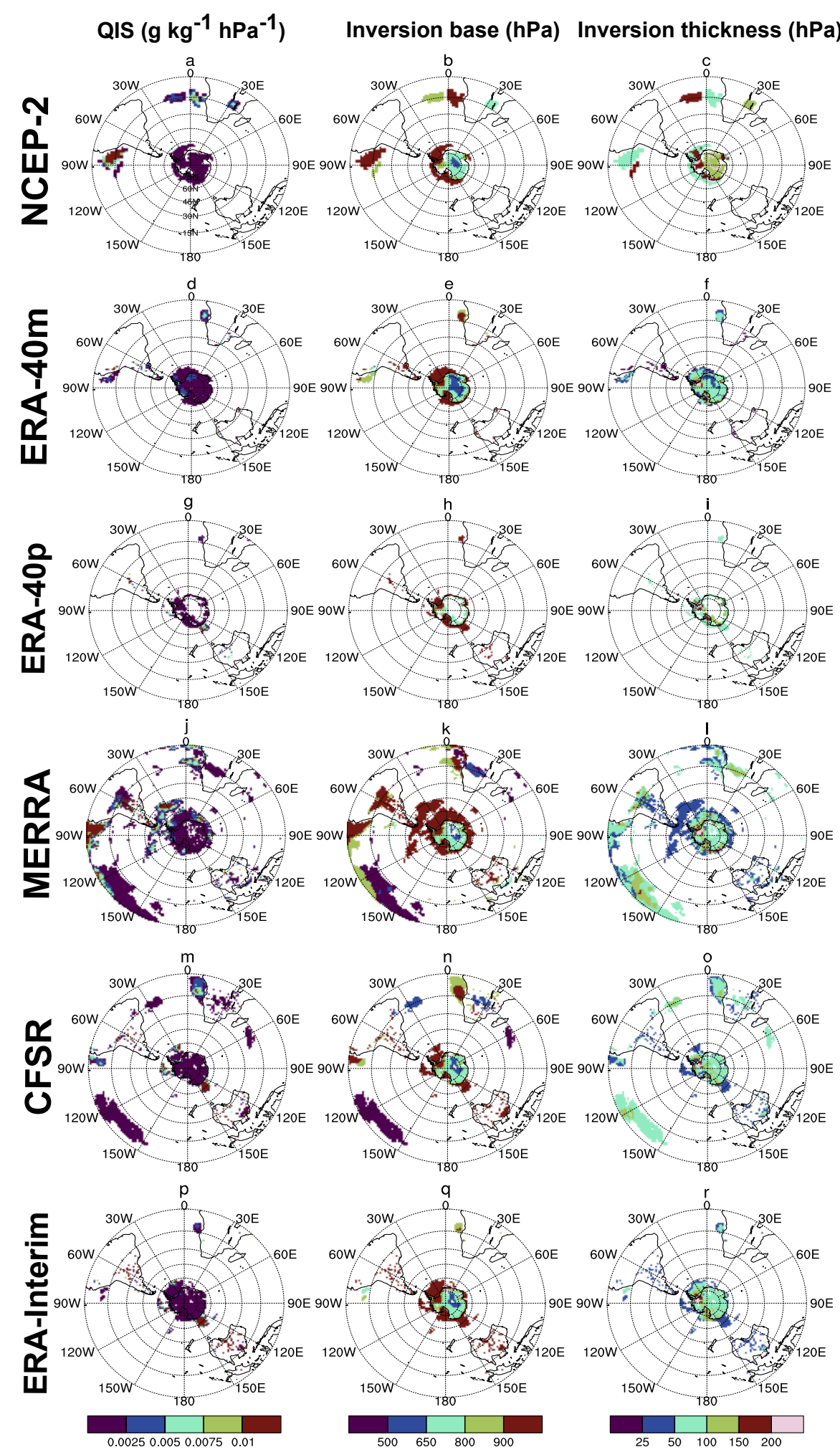

Fig. 5. Same as Fig. 4 except for July in the Southern Hemisphere. 

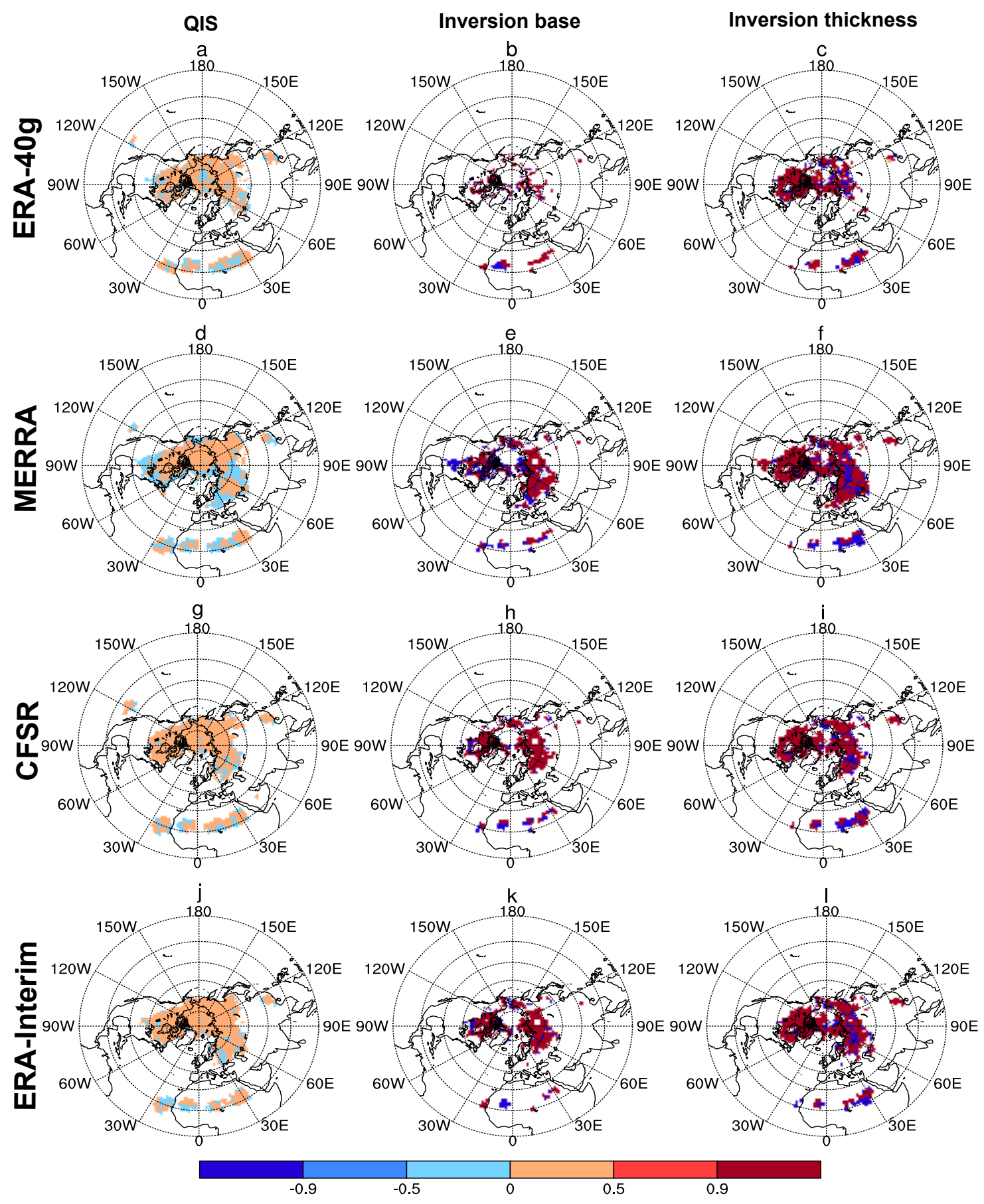

Fig. 6. The correlation in QIS, inversion base, and inversion thickness of NCEP-2 with ERA40g, MERRA, CFSR, and ERA-Interim. 

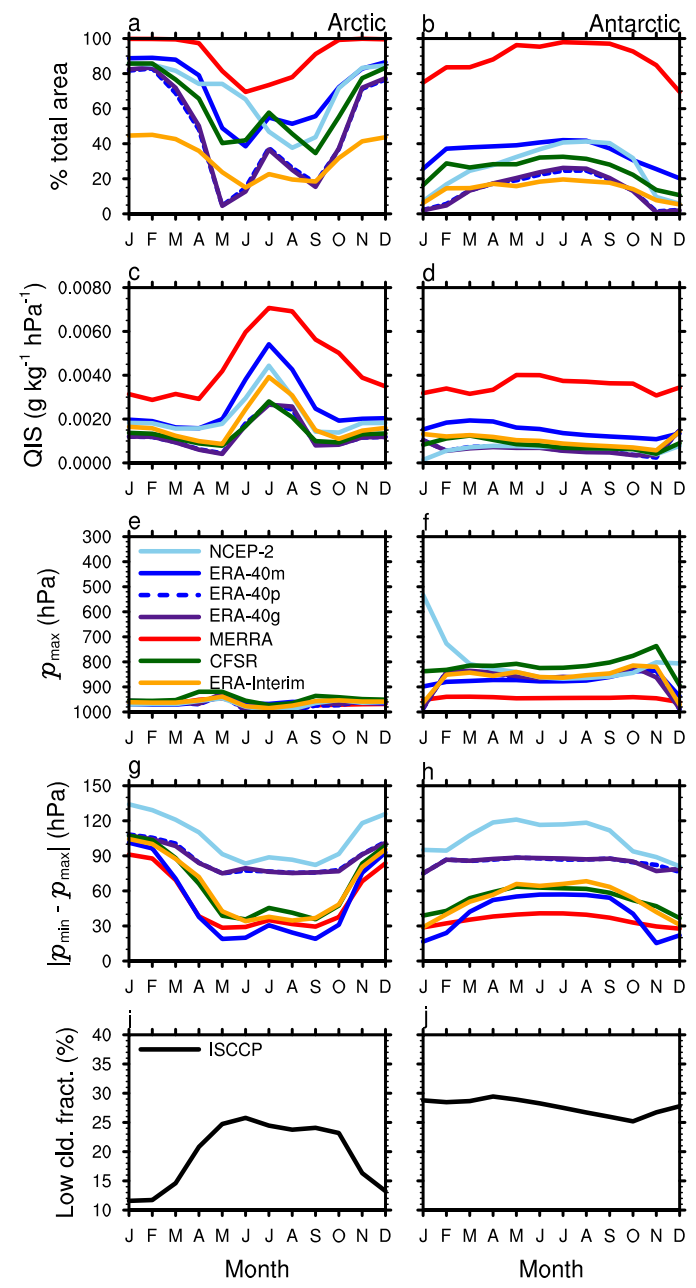

Fig. 7. (a,b) Maximum possible percentage of area covered by humidity inversions based upon the total area of all grids in which humidity inversions are possible every month plus area mean (c,d) inversion strength [QIS, Eq. (1)], (e,f) base pressure, and (g,h) thickness for only the grid cells that have an inversion poleward of $60^{\circ} \mathrm{N}$ (left column) and $45^{\circ} \mathrm{S}$ (right column). Also included is the area-mean low cloud fraction from the International Cloud Climatology Project (ISCCP) product (bottom row). 

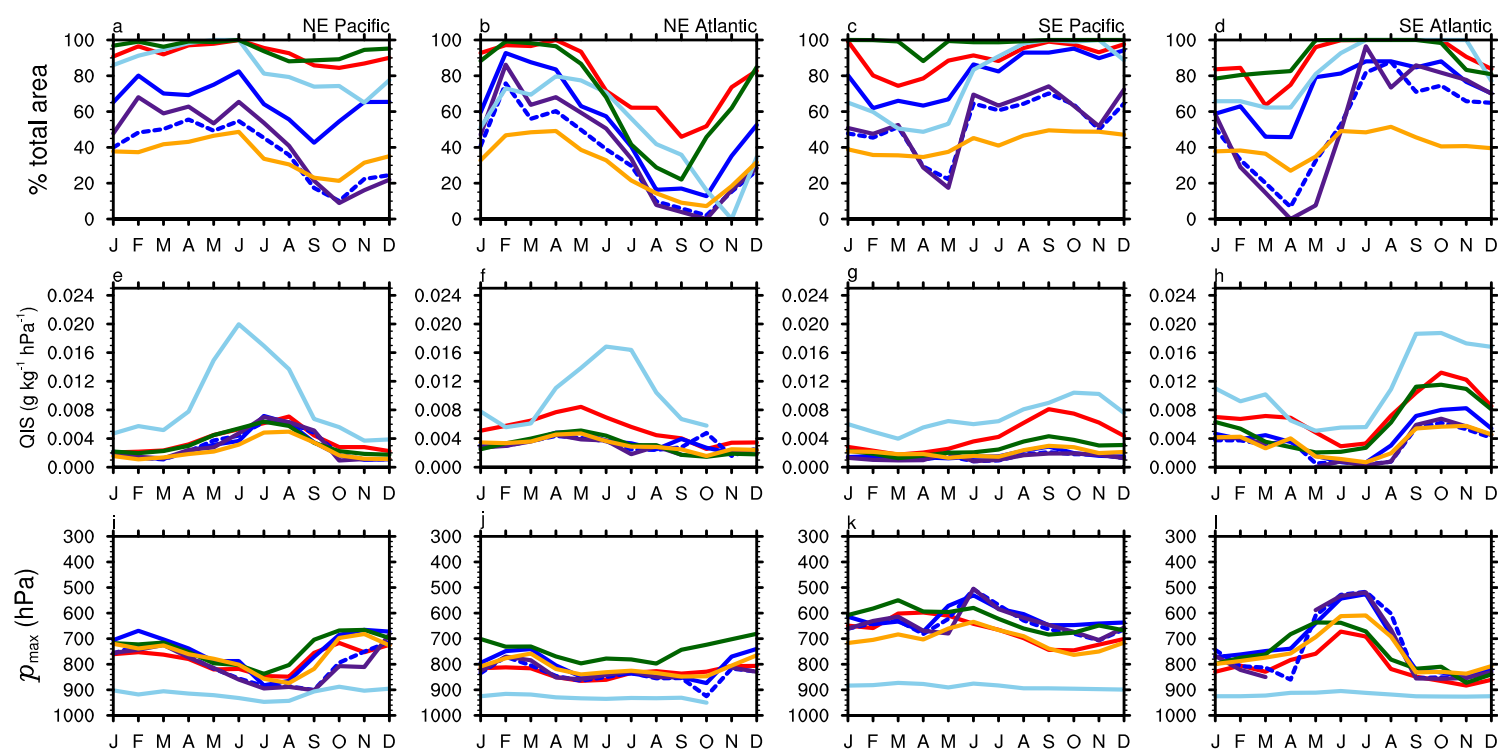

J F M A M J J A SON D
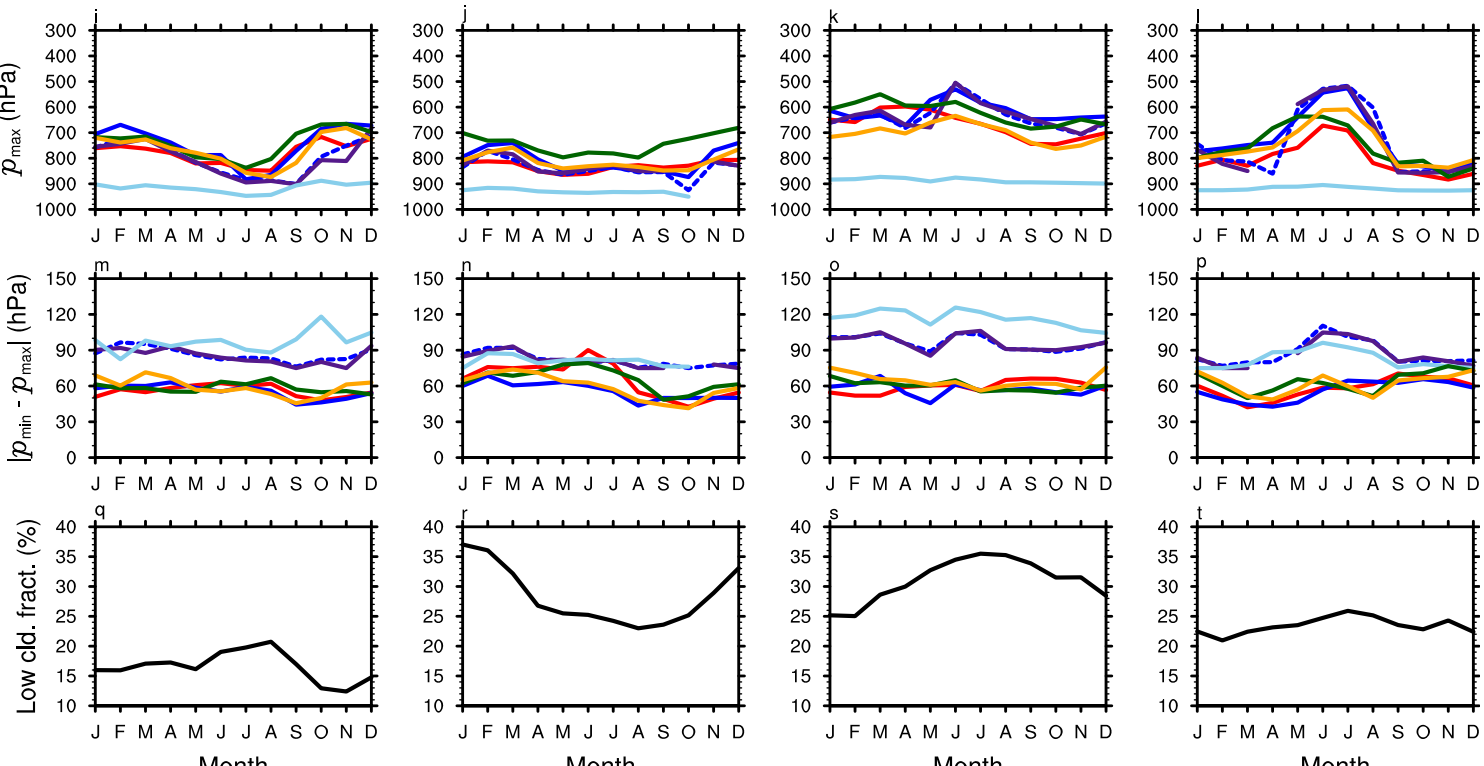

Month

Month

Month
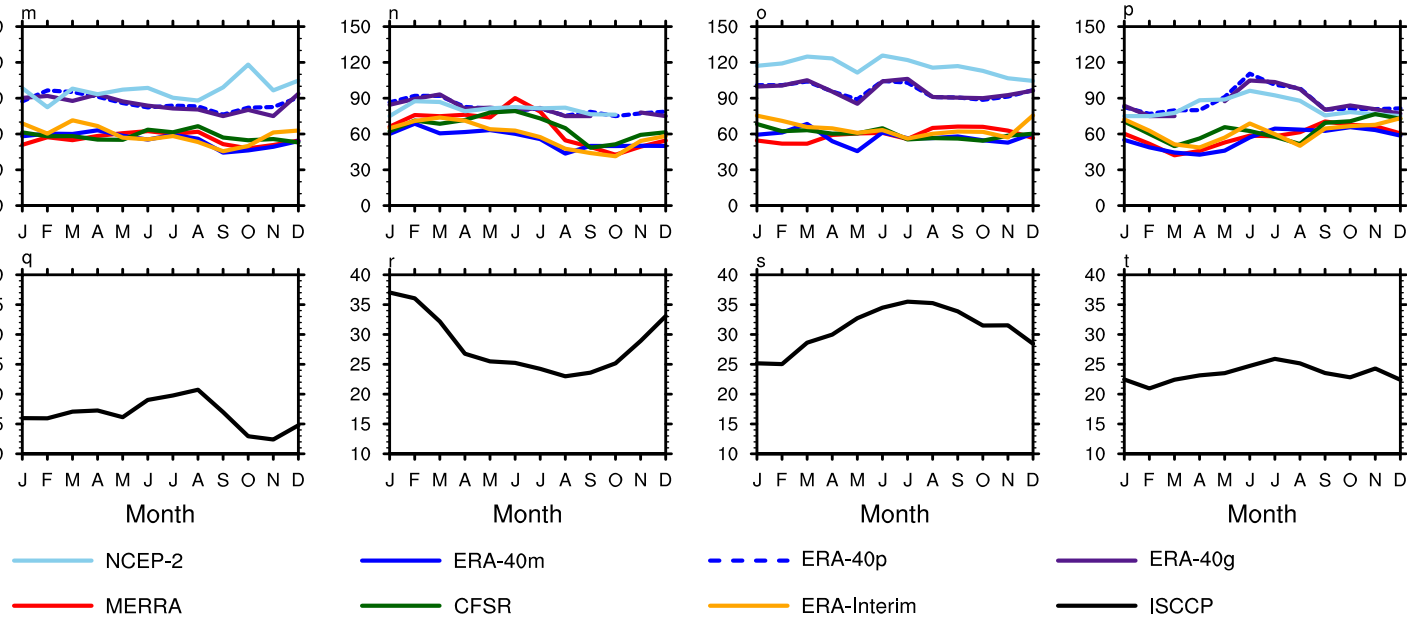

ERA-40g

ISCCP

Fig. 8. Same as Fig. 7 except for the subtropical stratus deck regions in the northeast (NE)

Pacific $\left(15^{\circ}-30^{\circ} \mathrm{N}, 110^{\circ}-140^{\circ} \mathrm{W}\right)$ (leftmost column), the NE Atlantic $\left(5^{\circ}-25^{\circ} \mathrm{N}, 20^{\circ}-\right.$

$\left.40^{\circ} \mathrm{W}\right)\left(2^{\text {nd }}\right.$ column $)$, the southeast $(\mathrm{SE})$ Pacific $\left(25^{\circ} \mathrm{S}-0^{\circ}, 80^{\circ}-110^{\circ} \mathrm{W}\right)\left(3^{\text {rd }}\right.$ column $)$, and the SE Atlantic $\left(25^{\circ} \mathrm{S}-0^{\circ}, 5^{\circ} \mathrm{W}-5^{\circ} \mathrm{E}\right)$ (rightmost column). 

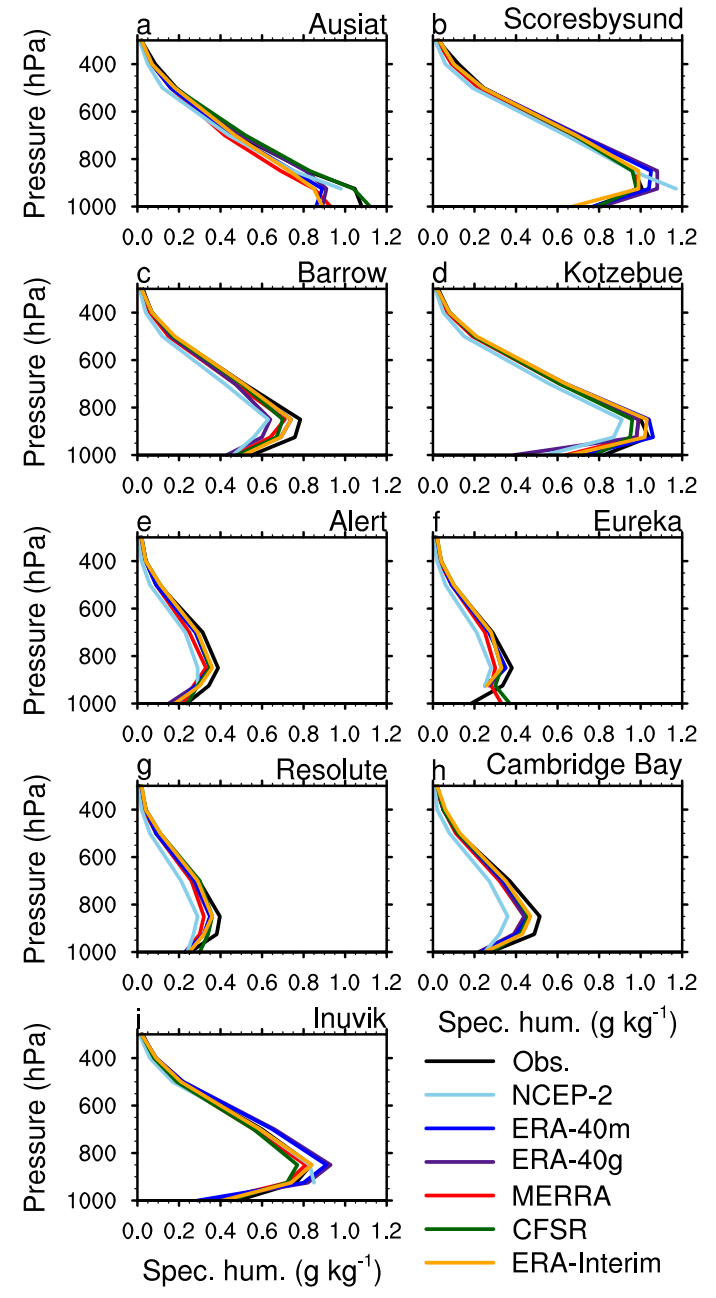

Fig. 9. Climatological mean January specific humidity profiles for 1994-2001 from rawinsonde observations and NCEP-2, ERA-40m, ERA-40g, MERRA, CFSR, and ERA-Interim at nine stations over the Arctic. 

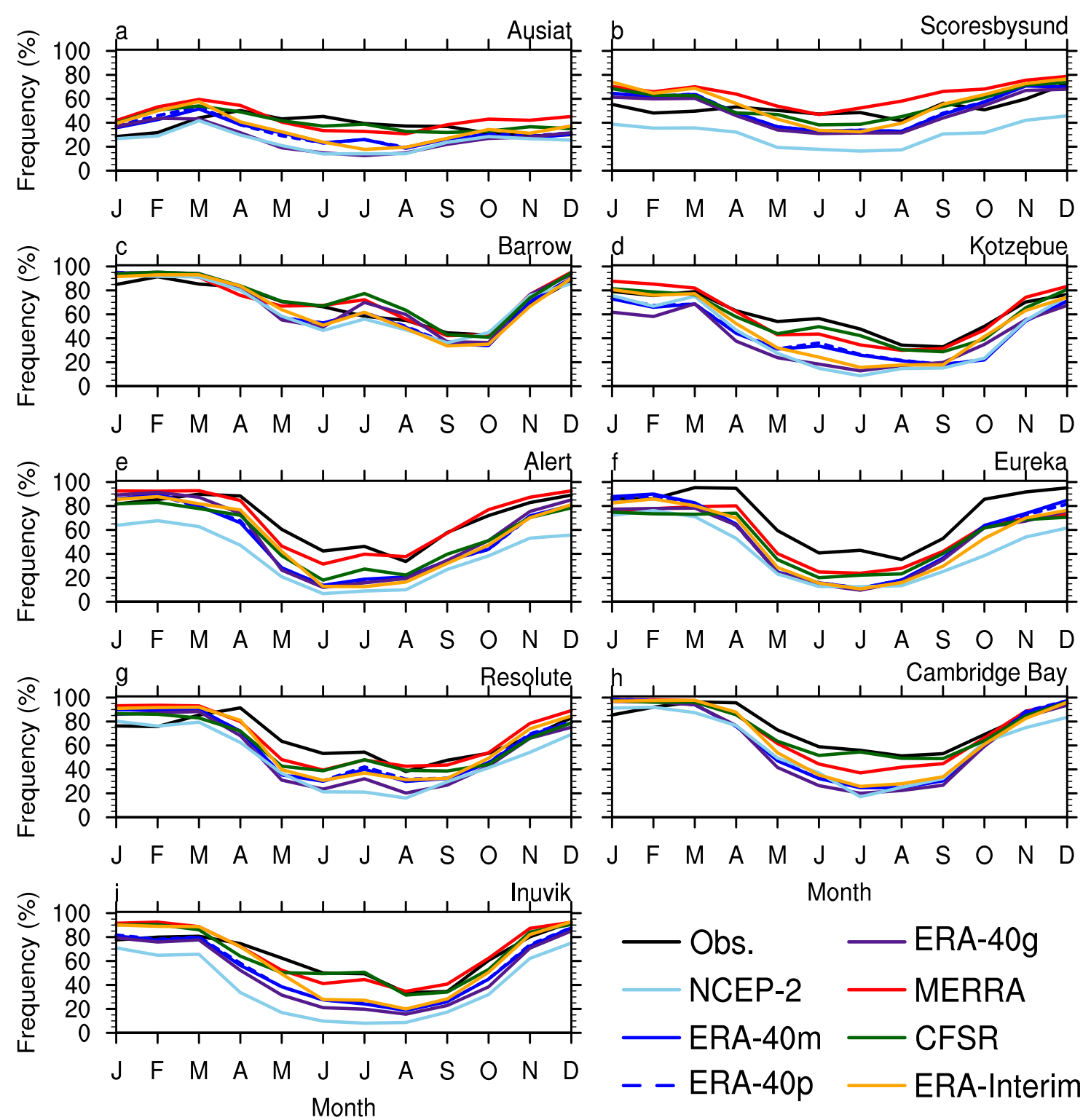

Fig. 10. Relative frequency of occurrence of humidity inversions per month for each of the Arctic stations in Fig. 9 in the rawinsonde data (obs.), NCEP-2, ERA-40m, ERA-40p, ERA-40g, MERRA, CFSR, and ERA-Interim. 

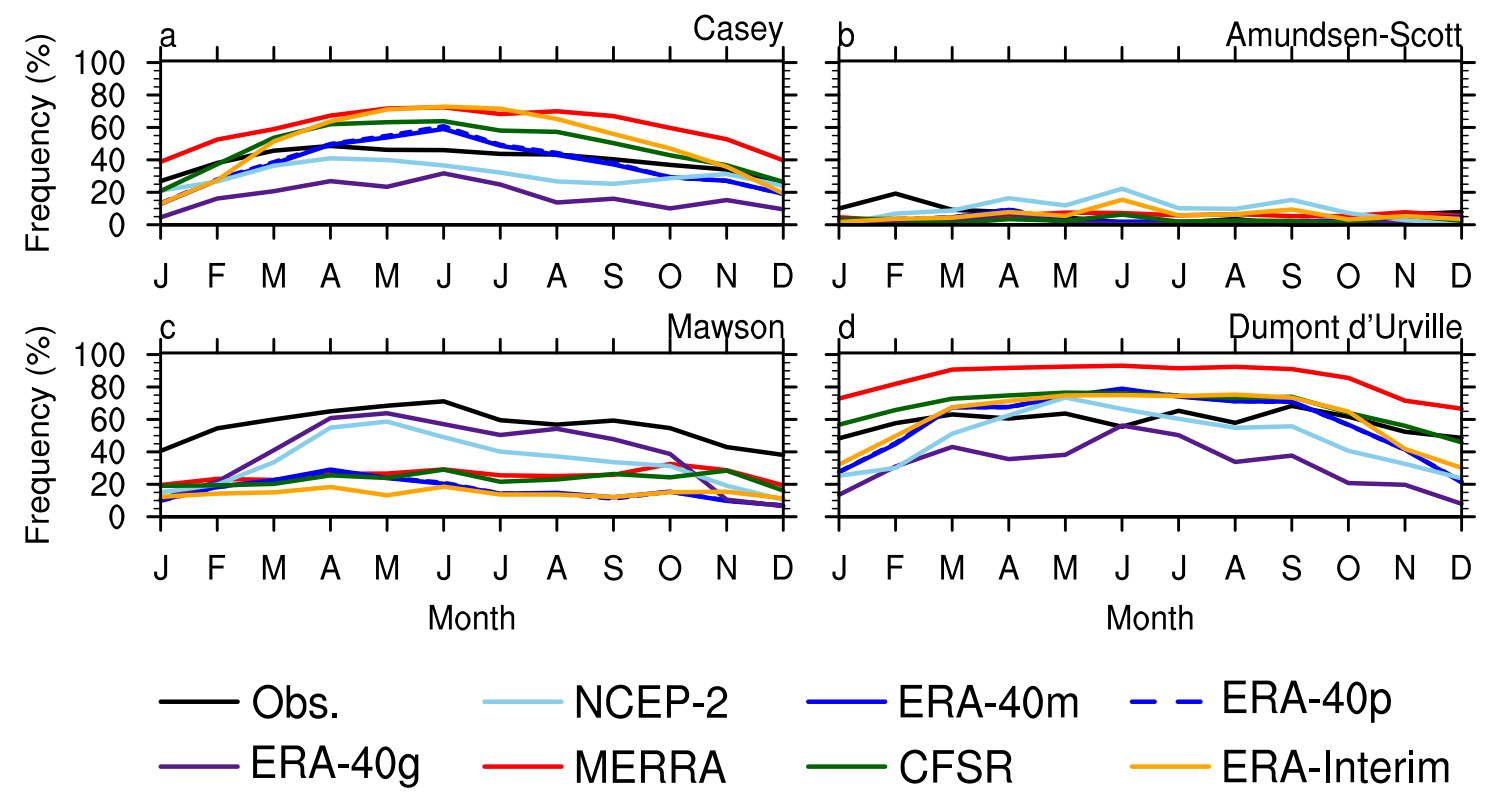

Fig. 11. Same as Fig. 10 except for the four Antarctic stations. 

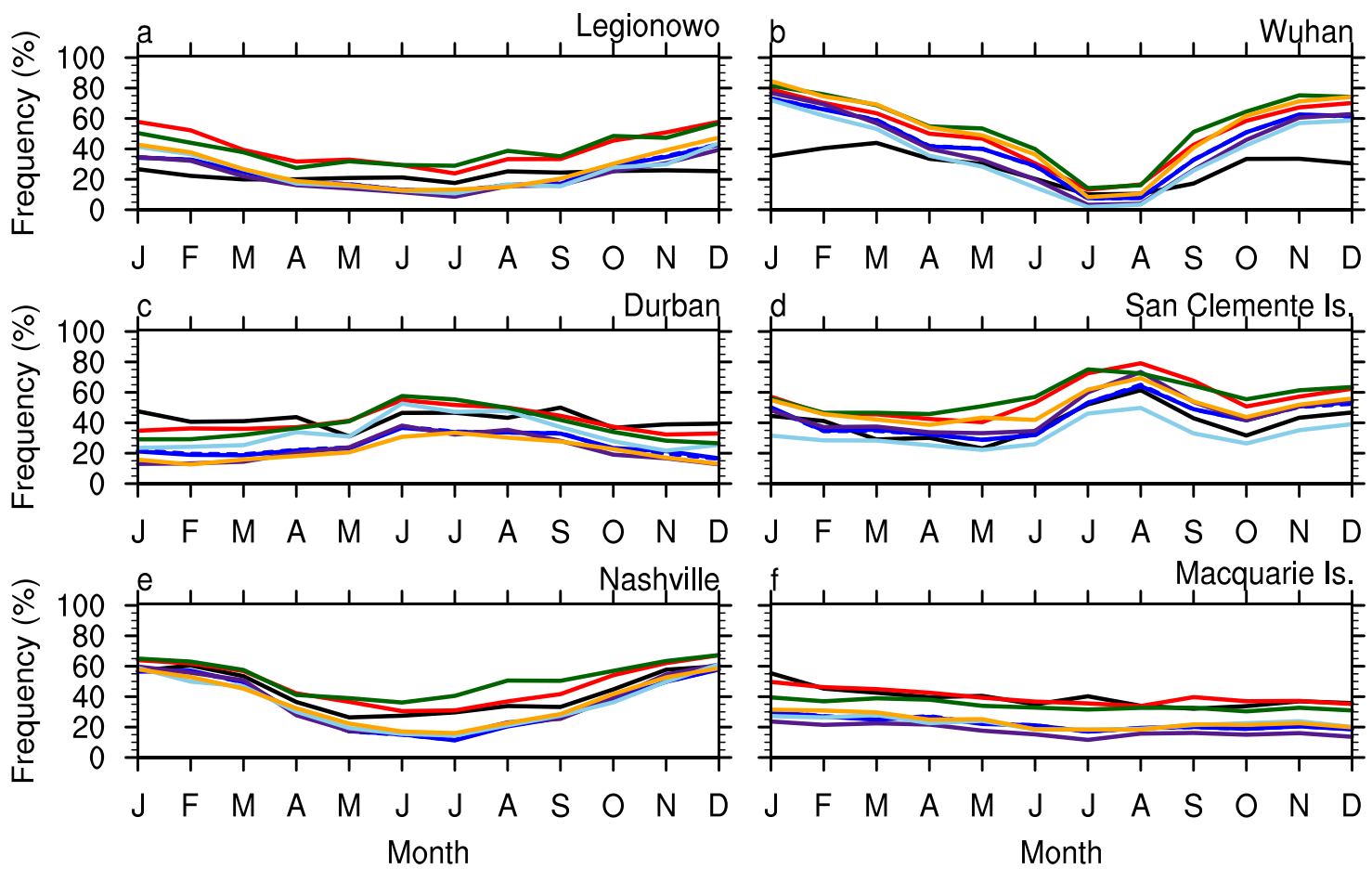

Obs. - NCEP-2 —ERA-40m - ERA-40p ERA-40g - MERRA - CFSR ERA-Interim

Fig. 12. Same as Fig. 10 except for the six mid-latitude stations. 

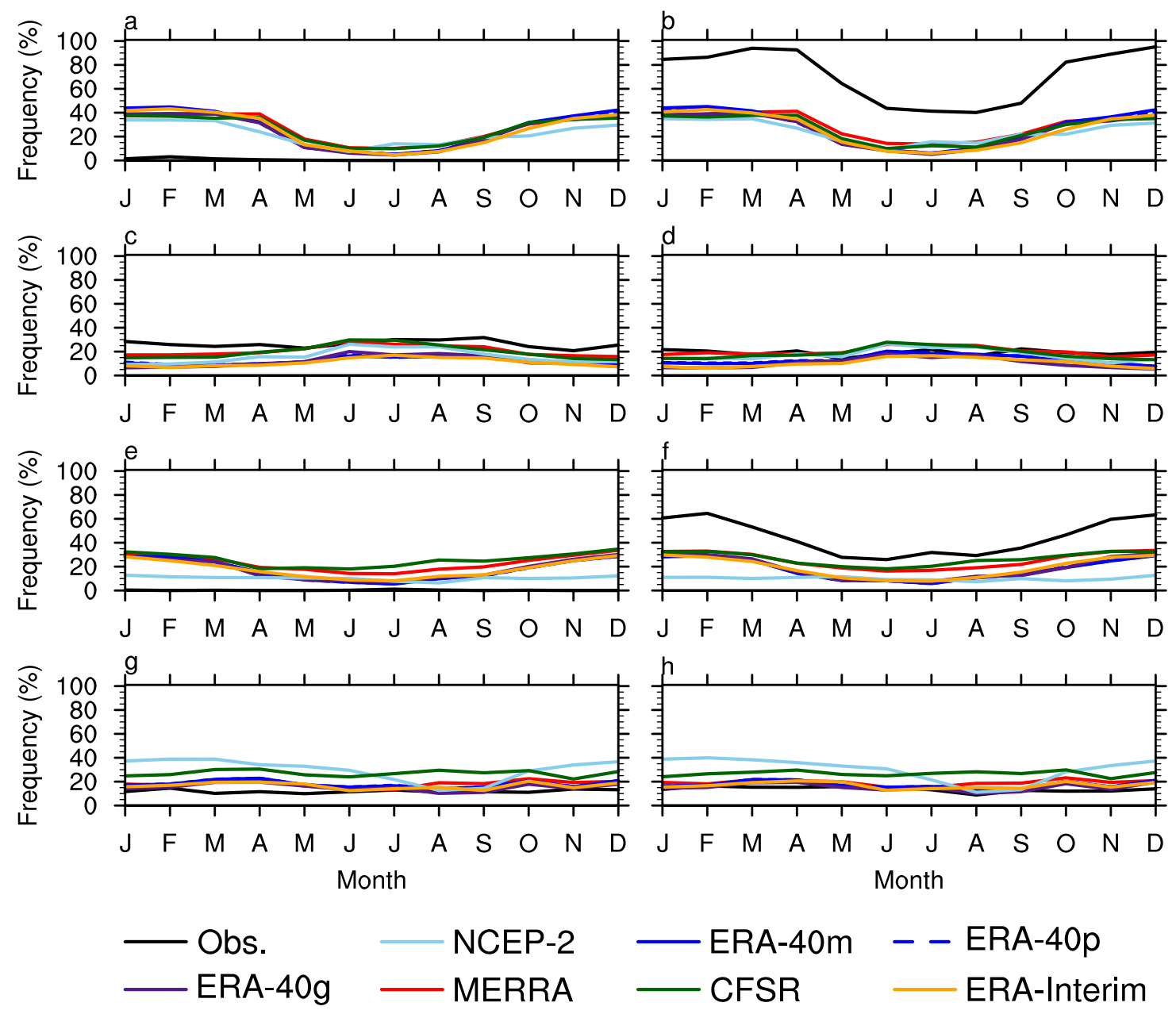

Fig. 13. Same as Fig. 10 except for $(a, b)$ Eureka, (c,d) Durban, (e,f) Nashville, and (g,h) Hilo only split into earlier than 6:00 and later than 18:00 LT (left) and between 6:00 and 18:00 LT (right). 


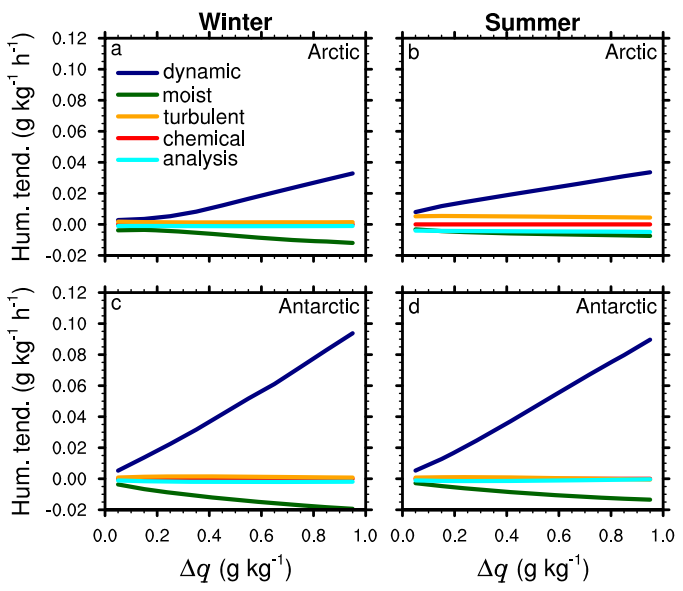

Fig. 14. The mean humidity tendencies due to dynamics ("dynamic"), moist physics ("moist"), turbulence ("turbulent"), chemical processes ("chemical"), and assimilation ("analysis") for $0.05 \mathrm{~g} \mathrm{~kg}^{-1}$ bins of the humidity difference across humidity inversions $(\Delta q)$ in the Arctic (top row, latitudes poleward of $60^{\circ} \mathrm{N}$ ) and Antarctic (bottom row, latitudes poleward of $45^{\circ} \mathrm{S}$ ) in local winter (left column) and summer (right column). 

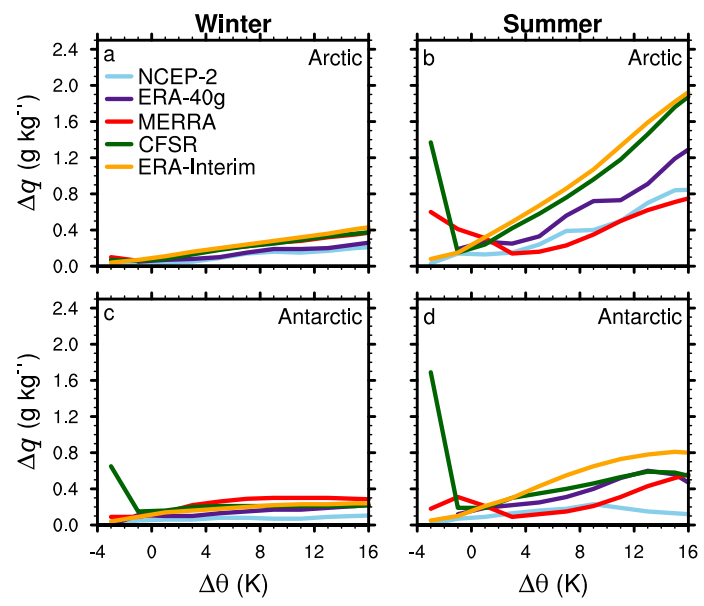

Fig. 15. The mean humidity difference across humidity inversions $(\Delta q)$ in the Arctic (top row, latitudes poleward of $60^{\circ} \mathrm{N}$ ) and Antarctic (bottom row, latitudes poleward of $45^{\circ} \mathrm{S}$ ) for 2-K bins of potential temperature difference across humidity inversions $(\Delta \theta)$ in local winter (left column) and summer (right column). 

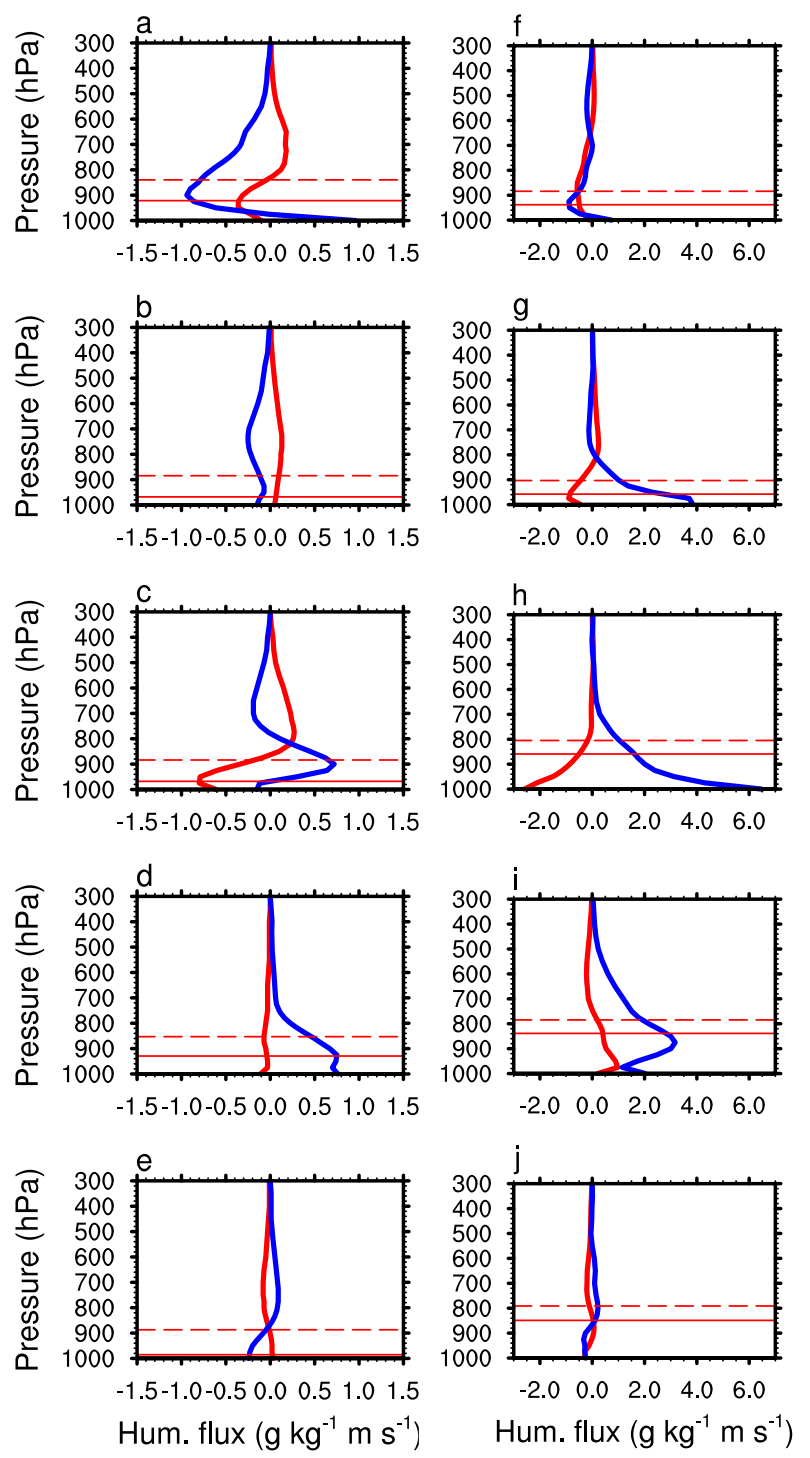

Fig. 16. Climatological mean January (left column) and July (right column) profiles of advective flux of specific humidity ( $-\left.u \Delta q\right|_{x}$ for the zonal direction, thick red lines, and $-v$ $\left.\Delta q\right|_{y}$ for the meridional direction, thick blue lines, where $u$ and $v$ are the horizontal wind speeds in the respective directions and $\left.\Delta q\right|_{x}$ and $\left.\Delta q\right|_{y}$ are the horizontal humidity differences in those respective directions) for 1994-2001 from MERRA at (a,f) Scoresbysund, (b,g) Barrow, (c,h) Kotzebue, (d,i) Eureka, and (e,j) Cambridge Bay. The mean humidity inversion bottom and top at each site are also indicated as the solid and dashed red lines, respectively, across. 


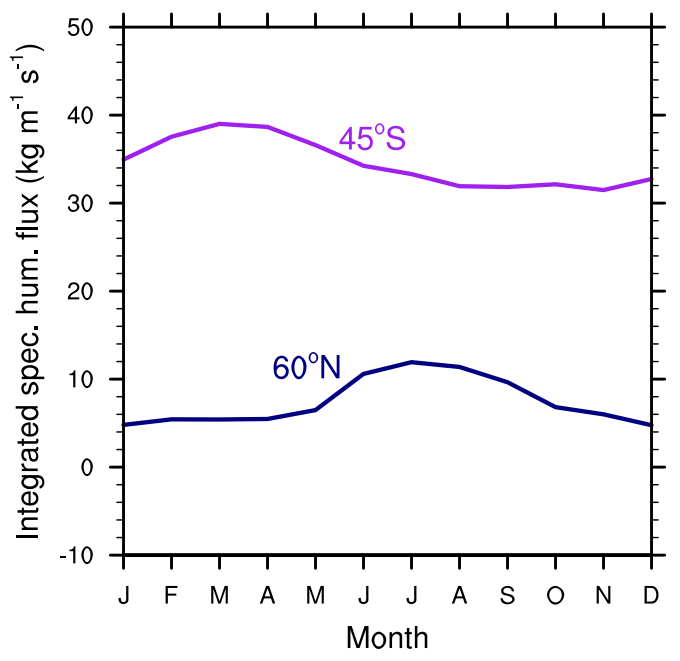

Fig. 17. The 1981-2000 mean annual cycle in MERRA tavg1_2d_int_Nx total column integrated specific humidity flux into the Arctic (across $60^{\circ} \mathrm{N}$ ) and the Antarctic (across $\left.45^{\circ} \mathrm{S}\right)$. 